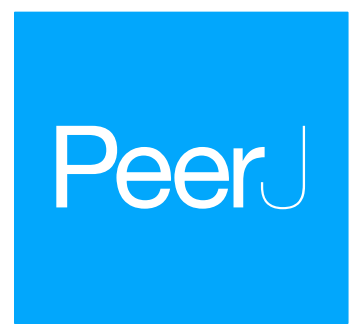

Submitted 19 September 2017

Accepted 20 December 2017

Published 25 January 2018

Corresponding author

Daniel Tyteca,

daniel.tyteca@uclouvain.be

Academic editor

Richard Bateman

Additional Information and Declarations can be found on page 26

DOI 10.7717/peerj.4256

Copyright

2018 Esposito et al.

Distributed under

Creative Commons CC-BY 4.0

OPEN ACCESS

\section{Characterization of sympatric Platanthera bifolia and Platanthera chlorantha (Orchidaceae) populations with intermediate plants}

Fabiana Esposito ${ }^{1}$, Nicolas J. Vereecken ${ }^{2}$, Maddalena Gammella ${ }^{3}$, Rosita Rinaldi ${ }^{3}$, Pascal Laurent ${ }^{4}$ and Daniel Tyteca ${ }^{1}$

${ }^{1}$ Earth and Life Institute-Biodiversity Research Centre, Université Catholique de Louvain, Louvain-la-Neuve, Belgium

${ }^{2}$ Agroecology Lab, Brussels Bioengineering School, Université libre de Bruxelles (ULB), Brussels, Belgium

${ }^{3}$ Department of Biology, University of Naples Federico II, Napoli, Italy

${ }^{4}$ Unit of General Chemistry, Université Libre de Bruxelles, Brussels, Belgium

\section{ABSTRACT}

Platanthera bifolia and P. chlorantha are terrestrial and rewarding orchids with a wide Eurasian distribution. Although genetically closely related, they exhibit significant morphological, phenological and ecological differences that maintain reproductive isolation between the species. However, where both species co-occur, individuals with intermediate phenotypic traits, often considered as hybrids, are frequently observed. Here, we combined neutral genetic markers (AFLPs), morphometrics and floral scent analysis (GC-MS) to investigate two mixed Platanthera populations where morphologically intermediate plants were found. Self-pollination experiments revealed a low level of autogamy and artificial crossings combined with assessments of fruit set and seed viability, showed compatibility between the two species. The results of the genetic analyses showed that morphologically intermediate plants had similar genetic patterns as the P. bifolia group. These results are corroborated also by floral scent analyses, which confirmed a strong similarity in floral scent composition between intermediate morphotypes and $P$. bifolia. Therefore, this study provided a much more detailed picture of the genetic structure of a sympatric zone between two closely allied species and supports the hypothesis that intermediate morphotypes in sympatry could reflect an adaptive evolution in response to local pollinator-mediated selection.

Subjects Ecology, Evolutionary Studies, Genetics, Plant Science

Keywords Platanthera, Orchidaceae, Hybridization, Moth pollination, Female fitness, Floral scent, Reproductive isolation, Phenotypic selection, Genetic markers, Morphometrics

\section{INTRODUCTION}

The evolution of reproductive isolation is a central topic in evolutionary biology. Flowering plants have evolved different ways to remain reproductively isolated from their congeners through various pre- and/or post-pollination barriers (Coyne \& Orr, 2004; Rieseberg \& Willis, 2007).

Orchids, a large and widespread family of flowering plants, are well known for their remarkable floral diversity. Ever since Darwin (1862), orchid biology has focused on 
the fundamental causes of species richness and morphological diversity (Cozzolino \& Widmer, 2005; Schlüter \& Schiestl, 2008). Much of this diversity is associated with intricate relationships with pollinators, and has often been attributed to adaptation to specific pollinators (e.g., Johnson, Linder \& Steiner, 1998) — an estimated 60\% of all orchid species only have a handful of recorded pollinator species (Tremblay, 1992).

Pollinators act as a driving force in the reproduction and diversification of orchids (Cozzolino \& Widmer, 2005) because they contribute to the establishment of reproductive isolation between species (Van der Cingel, 1995; Cozzolino, D'Emerico \& Widmer, 2004; Moccia, Widmer \& Cozzolino, 2007; Stökl et al., 2008; Schatz et al., 2010). Appropriate strategies for attracting pollinators and ensuring that cross-pollination is taking place efficiently are essential in the adaptation and evolution of the species. Particularly, orchids are known to have developed various and original strategies (reviewed by Jersáková, Johnson \& Kindlmann, 2006). Given their strong influence on pollination efficiency, the adaptive value of floral traits displayed by orchids has received considerable attention from evolutionary biologists (e.g., Edens-Meier \& Bernhardt, 2014).

Despite the presence of isolation barriers among species, natural hybridization is one of possible evolutionary processes that may occur in plants (Stebbins, 1959; Arnold, 1992; Rieseberg, 1995; Abbott et al., 2013). Considered as an important driving force in angiosperm diversification and speciation, this mechanism can originate "emergent" floral novelties between sympatric taxa (e.g., Stebbins, 1959; Wissemann, 2007; Soltis \& Soltis, 2009; Whitney et al., 2010). The orchid family is known for having poorly developed genetic barriers to hybridization, even between genera (Dafni \& Ivri, 1979; Van der Cingel, 1995; Schatz et al., 2010). Indeed, whenever genetically related taxa co-occur with an overlap in flowering periods and soil preferences, they may share pollinators and produce hybrids (e.g., Cozzolino et al., 2006).

Platanthera Rich., which belongs to subtribe Orchidinae (subfamily Orchidoideae), has apparently undergone an exceptional radiation in floral form and pollination syndrome (Hapeman \& Inoue, 1997). The geographic distribution of Platanthera species—also known as "butterfly orchids"-covers most of the temperate zone throughout the Northern Hemisphere (Hultén \& Fries, 1986) and this orchid genus encompasses five species in mainland Europe, two of which are widespread: P. chlorantha (Custer) Rchb. and P. bifolia (L.) Rich. (Bateman et al., 2009). They can be distinguished on the basis of the caudicle length and the distance between the viscidia, which seem to be the main discriminating factors between the two species (Nilsson, 1983; Nilsson, 1985). These two closely related species exhibit not only morphological differences, but also distinct ecological preferences (P. chlorantha favouring dry, calcareous grasslands, while P. bifolia will be typically found in slightly wet to humid meadows on acidic soil, although ecotypes growing on drier, calcareous soils are frequent). Additionally, several pre-pollination barriers have been established between the two species (Nilsson, 1983).

Plants exhibiting intermediate morphological characteristics in mixed populations of the two species have often been interpreted as hybrids (e.g., Nilsson, 1985; Maad \& Nilsson, 2004; Claessens \& Kleynen, 2006; Bateman \& Sexton, 2008; Bateman, James \& Rudall, 2012). Despite the large number of presumed hybrids recorded between the two Platanthera species 
(Bateman, 2005; Claessens, Gravendeel \& Kleynen, 2008), genetic analyses that directly compare putative hybrids with the sympatric parental species are rare (but see Bateman, James \& Rudall, 2012). Studying the morphology and the genetic constellation of sympatric populations using molecular markers may provide an opportunity to identify hybridization between orchid species and help investigate the type and strength of reproductive isolation (Martinsen et al., 2001; Lexer et al., 2005; Moccia, Widmer \& Cozzolino, 2007; Cortis et al., 2009). Recently, a study on some Western-European Platanthera populations composed almost exclusively of intermediate looking individuals, based on morphology and molecular markers, concluded that such individuals were not hybrids, but constitute an independent lineage, distinct from both widespread species (Durka et al., 2017), and described as a distinct species with the name P. muelleri (Baum \& Baum, 2017).

The level of geitonogamy was observed to be higher in P. bifolia than in P. chlorantha because the latter has a pollinarium-bending mechanism that prevents deposition of the pollinia directly after removal (Maad \& Nilsson, 2004; Maad \& Reinhammar, 2004). This process may also affect the probability of hybrid formation (Ishizaki, Abe $\backsim$ Ohara, 2013). An allopatric $P$. bifolia population with a high degree (i.e., almost $60 \%$ ) of self-pollination was found by Brzosko (2003), although self-pollination in Platanthera species is considered generally rare (Nilsson, 1983; Maad, 2002).

In the genus Platanthera, floral scent plays a crucial role in guiding pollinators to the flowers (Nilsson, 1983; Nilsson, 1985; Tollsten \& Bergström, 1993). A strong fragrance is emitted after dusk, when pollinators (nocturnal moths) are most active (Nilsson, 1983; Nilsson, 1985; Tollsten \& Bergström, 1993; Hapeman \& Inoue, 1997; Plepys et al., 2002a; Plepys, Ibarra \& Lofstedt, 2002b). Floral fragrances of Platanthera have been classified into linaloolic, lilac, geraniolic and benzenoic chemotypes depending on the main class of compounds present in the blend (Tollsten \& Bergström, 1993; Plepys et al., 2002a; Plepys, Ibarra \& Lofstedt, 2002b). Lilac volatiles together with various benzenoids are strong attractants, being the most important compounds of floral scent in attracting moths (Plepys et al., 2002a; Plepys, Ibarra \& Lofstedt, 2002b). Furthermore, a change in floral scent composition has been suggested by Nilsson (1983) and Nilsson (1985)) to prevent effective cross-pollination between both species (Nilsson, 1978; Tollsten \& Bergström, 1993), by acting as a reproductive barrier via ethological mechanisms. Tollsten \& Bergström (1993) discovered that important inter-individual and inter-population variation in floral scent exists, and may act as an adaptation in order to attract a wider range of local pollinator species.

In this study, we investigated allopatric and two mixed populations of Platanthera bifolia and P. chlorantha in which morphologically intermediate individuals have been classified firstly as hybrids. In order to determine whether intermediates are indeed hybrids, or constitute an independent lineage, or represent mere variants of one of the two species, we performed a comparative analysis by comparing (i) the floral morphology (ii) the genetic profiles morphotypes, and (iii) the chemical characteristics of floral scents between allopatric, sympatric species and mixed populations. Furthermore, we investigated (iv) the reproductive success in each population by quantifying fruit set, (v) the genomic 
compatibility of the two species by performing manual self and cross-pollination, and (vi) the presence and the strength of pre and post-pollination barriers (pre and post-zygotic).

\section{MATERIALS AND METHODS Study species and sampling sites}

Platanthera bifolia and P. chlorantha are two terrestrial orchids with a wide Eurasian distribution. The flowering period in Central Europe of both species occurs between May and July, partly overlapping in areas of sympatry (Delforge, 2006). The inflorescences of Platanthera display 10-25 white, hermaphroditic flowers, which open sequentially acropetally and possess a long, slender nectariferous spur as a backward extension of the lip. The length of the spur varies geographically in North-western Europe, and it is also positively correlated to the proboscis length of local pollinators (Darwin, 1862; Nilsson, 1985; Maad \& Nilsson, 2004; Boberg \& Agren, 2009; Boberg et al., 2014). Also, the distance between the viscidia is an adaptation to various organs on the pollinator's head (Nilsson, 1983).

Although the two species are very close genetically (Bateman, James \& Rudall, 2012) and show the same diploid chromosome number $(2 n=42)$ (Nilsson, 1983), a few floral traits, or combination thereof, allow separation of individuals into discrete groups matching the two species (Darwin, 1862; Nilsson, 1978; Nilsson, 1983; Nilsson, 1985). P. bifolia presents a small column with a narrow connective and anther pockets set almost parallel to each other, with a distance between the viscidia ranging between 0.2 and $1.1 \mathrm{~mm}$, while the pollinium has a very short caudicle $(0.2-0.5 \mathrm{~mm})$; these characteristics imply that pollinaria will be attached to the pollinator's proboscis (Figs. 1A and 1B). The species is predominantly pollinated by hawkmoths (Sphingidae) (Nilsson, 1983).

By contrast, the column of $P$. chlorantha is wide, with a broad connective and the anther pockets set strongly divergent at the base. The pollinium has a relatively long caudicle $(1.2-2.2 \mathrm{~mm}$ ) and the distance between the viscidia is between 2.3 and $4.9 \mathrm{~mm}$ (Figs. 1E and $1 \mathrm{~F}$ ). This is considered to be an adaptation for attachment to the eyes of pollinators, which are mostly noctuids (Noctuidae) (Nilsson, 1983). In the intermediate plants the distance between the viscidia is, on average, larger than in P. bifolia and smaller than in P. chlorantha (1.3-2.3 mm), while the caudicle length lies between 0.6 and $1.2 \mathrm{~mm}$ (Figs. 1C and 1D). We based a priori identification of the individuals on these values intervals for the two specified characters (caudicle length and distance between the viscidia).

This intermediate form of the gynostemium may induce an inadequate attachment of pollinaria to the hairy labial palps of the moths (Nilsson, 1978). Therefore, the pollen of putative hybrids will often be lost because it will not reach the stigmas of other Platanthera individuals. As a result, crossing between hybrid derivatives seems poorly effective (Nilsson, 1983). This process should contribute to pre-pollination isolation and help to maintain the genetic integrity of each species (Nilsson, 1983; Van der Cingel, 1995; Waser, 2001; Cozzolino, D'Emerico \& Widmer, 2004; Scopece et al., 2007).

We investigated sympatric populations with $P$. bifolia, $P$. chlorantha and intermediate morphotypes in two sites in Southern Belgium. As shown in Table 1, the two populations 

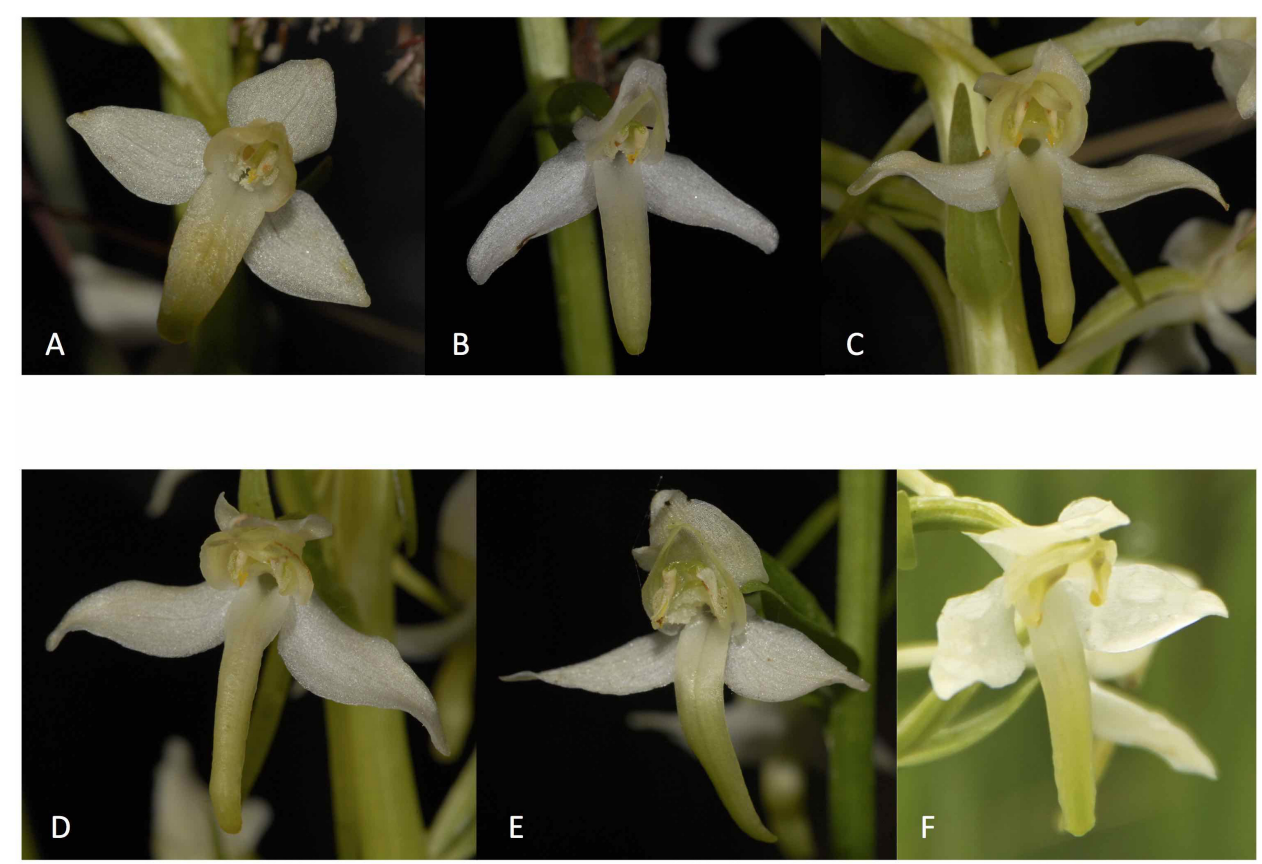

Figure 1 Pictures showing flowers of the plants investigated. (A) P. bifolia, allopatric population, Navaugle, 8 July 2013. (B) P. bifolia, mixed population, Bois Niau, 3 June 2011. (C) P. bifolia, intermediate looking plant, Botton, 25 May 2011. (D) P. bifolia, intermediate looking plant, Botton, 25 May 2011.

(E) P. chlorantha, mixed population, Bois Niau, 21 June 2010. (F) P. chlorantha, allopatric population, Transinne, 4 July 2013. Pictures deposited in the Herbarium of the Belgian National Botanic Garden (BR), Meise (all pictures D. Tyteca, except part (F): F. Esposito). See Appendix for correspondence.

Full-size DOI: $10.7717 /$ peerj.4256/fig-1

\begin{tabular}{|c|c|c|c|c|c|c|}
\hline Station & Taxon & $\begin{array}{l}\text { Morphology + } \\
\text { fruit set }\end{array}$ & AFLP & Scent & $\begin{array}{l}\text { Self- } \\
\text { pollination }\end{array}$ & $\begin{array}{l}\text { Cross } \\
\text { pollination }\end{array}$ \\
\hline \multirow[t]{3}{*}{ Botton } & P. bifolia & 30 & 20 & 10 & 6 & 15 \\
\hline & Intermediate & 33 & 20 & 7 & 6 & \\
\hline & P. chlorantha & 50 & 16 & 10 & & 15 \\
\hline \multirow[t]{3}{*}{ Bois Niau } & P. bifolia & 20 & 20 & & & \\
\hline & Intermediate & 18 & 18 & & & \\
\hline & P. chlorantha & 14 & 14 & & & \\
\hline Navaugle & P. bifolia & 36 & 20 & & 4 & 15 \\
\hline Transinne & P. chlorantha & 41 & 20 & & 4 & 15 \\
\hline Total & & 242 & 148 & 27 & 20 & 60 \\
\hline
\end{tabular}

were sampled in the Calestienne region, one on a calcareous grassland (Tienne de Botton) and the other on a light birch-ash wood (Bois Niau). In addition, two allopatric populations were sampled: in the Famenne region (Navaugle) for P. bifolia, in a semi-wet meadow on acidic soil, and in the Ardenne region (Transinne) in a semi-wet neutral meadow for $P$. chlorantha. In the sympatric sites, plants were classified based on the values firstly suggested by Nilsson (1983), which will be used as the starting point for the investigations to 
be conducted. In each site, plants showing good flowering conditions (i.e., fully flowering, with fresh flowers) were sampled randomly for the investigation. Selected individuals sampled for the morphological measurements were also subjected to genetic and chemical analyses (Table 1). Permissions to operate in the field in Nature Reserves were obtained from Walloon authorities in charge of Nature Protection (Département Nature et Forêts, Département de l'Étude du Milieu Naturel et Agricole). Photographic material of the studied populations was deposited in the herbarium of the Belgian National Botanic Garden (BR).

\section{Floral morphology and reproductive success: statistical analyses}

In order to characterize the floral morphology of the different populations, four floral traits were measured: spur length $(\mathrm{mm})$, caudicle length $(\mathrm{mm})$, distance between the viscidia (mm) and labellum length (mm) (Nilsson, 1983; Nilsson, 1985; Claessens \& Kleynen, 2006).

To test the null hypothesis of no morphological differences among taxa, we first conducted a non-parametric Multiple Response Permutation Procedure (MRPP) using VEGAN package version 2.0-5, with the average Bray-Curtis distances among samples weighted to group size and 999 random permutations (Mielke \& Berry, 2001; McCune \& Grace, 2002). Then, an analysis of similarities (ANOSIM) was performed using the average Bray-Curtis distances among samples and 1,000 permutations with the VEGAN package (version 2.0-5; Oksanen et al., 2012) in R (R Core Team, 2015) as an alternative way to test statistically whether or not there is a significant difference in morphological traits.

Furthermore, we carried out a multiple comparison with the Kruskal-Wallis test to evaluate the degree of association between samples and the Dunn's test (Dunn-Sidakprocedure) to determine which of the sample pairs are significantly different for each morphological trait.

In addition, we performed a canonical discriminant analysis using the morphological data. We applied a stepwise method with an $F$ value of 3.84 to enter a variable, and $F$ value of 2.71 to remove it (Moccia, Widmer \& Cozzolino, 2007; Jacquemyn et al., 2012a). The discriminant function was derived using trait measurements from the two allopatric Platanthera populations. Then, we used the function to estimate the average floral morphology of each plant present in the sympatric zone (Moccia, Widmer \& Cozzolino, 2007) that was used as morphological index. This analysis was conducted using the SPSS 21.0 statistical package (SPSS Inc., Chicago, IL, USA). We also performed a multivariate analysis (PCA) on correlation matrix, using the function prcomp, to summarize the information of morphological data. In addition, to compare fruit set (number of fruits/number of flowers) between Platanthera groups in both sympatric sites a multiple comparison with the Kruskal-Wallis test coupled with Dunn's test (Dunn-Sidak-procedure) was performed. These statistical analyses were performed in the software environment $\mathrm{R}$ version 3.2.1 (R Core Team, 2015).

\section{Manual crosses and pre and post-pollination isolation index}

To determine the level of compatibility between species, experimental crosses were carried out in the sympatric area of Botton. Fresh flowers with intact pollinaria were randomly 
selected. Interspecific hand-pollinations were performed by removing pollinaria through touching the viscidia with a plastic toothpick and placing them on the stigmas of plants of the other species. Crossing combinations were performed bi-directionally ( $P$. bifolia/P. chlorantha and $P$. chlorantha/P. bifolia) with each plant providing and receiving pollen, and included control-treatments (Table 1).

To prevent the potential negative effects of over-pollination on fruit set and seed viability, a maximum of three flowers per individual were hand-pollinated. This experiment is based on Xu et al. (2011). To prevent insect visits after experimental crossings, each inflorescence was covered with a pollination bag (to prevent pollination by insects) before and after the cross-pollination. Fruit initiation and development were monitored until fruits were mature (about one month after pollination). All crossed capsules were collected from the two investigated sympatric species and stored in silica gel. In addition, eight allopatric and 12 sympatric individuals of $P$. bifolia and intermediate morphotypes (Table 1) were also covered with a pollination bag before anthesis to determine the degree of autonomous self-pollination.

Seeds produced by interspecific (hand pollinations), intraspecific crosses and also in the autonomous self-pollination treatment were harvested and brought to the laboratory. Seeds were observed under a microscope (100× magnification) to distinguish seeds containing one large viable embryo from non-viable seeds (i.e., small or aborted embryos or no embryo). Samples of 300 seeds per fruit were scored in order to estimate the percentage of viable seeds for each fruit (Xu et al., 2011). The significance of different seed viability among interspecies and intraspecies crosses was assessed using Student's $t$-test, after normality testing of data distribution by the Shapiro test (Royston, 1982).

We also examined and quantified the effect of post-pollination barriers using indices of reproductive isolation (RI) (Kay, 2006). Based on the methods proposed in Scopece et al. (2007) and Marques et al. (2014), we estimated two measures of post-pollination reproductive isolation. We firstly estimated the post-pollination pre-zygotic isolation index as the proportion of fruits formed after interspecific crosses in relation to the proportion of fruits formed after intraspecific crosses:

RI post - pollination $_{\text {pre-zygotic }}=1-\frac{\text { average fruit set after interspecific crosses }}{\text { average fruit set after intraspecific crosses }}$.

Then, we calculated post-zygotic isolation index as the percentage of viable seeds from interspecific crosses in relation to the proportion of viable seeds obtained from intraspecific crosses, describing the embryo mortality:

RI post - pollination post-zygotic $=1-\frac{\text { viable seeds formed after interspecific crosses }}{\text { viable seeds formed after intraspecific crosses }}$.

In addition, since flowering time is known to contribute to the maintenance of phenotypic polymorphism, we estimated the strength of RI value, which corresponds to flowering phenology. The overall flowering period was recorded for both Platanthera species only at Botton site. Plants were checked every three days during one flowering season (2015). For the investigation of flowering phenology we examined: the beginning of blooming (first flower opened), the end of the flowering period (when the last flower opened). The RI 
phenology index was calculated as: $\mathrm{RI}_{\text {phenology }}=1-$ (overlapping flowering period between species (number of days)/flowering period (number of days)) (Ma et al., 2016).

\section{DNA extraction and AFLP analysis}

In each population, a leaf fragment of ca. $2 \mathrm{~cm}^{2}$ was collected for 10-20 plants of each of the taxa (see Table 1), and the plant tissue was desiccated using silica gel in individually sealed plastic bags. Genomic DNA was extracted using a slight modification of the CTAB protocol of Doyle \& Doyle (1987). Plant leaf material was macerated in $900 \mu \mathrm{L}$ of standard CTAB buffer, incubated at $60{ }^{\circ} \mathrm{C}$ for $30 \mathrm{~min}$, extracted twice with chloroform-isoamyl alcohol, precipitated with isopropanol and washed with $70 \%$ ethanol. Precipitated DNA was then resuspended in $30 \mu \mathrm{L}$ of distilled water. We obtained AFLP fragments using the methods of Vos et al. (1995), with modifications as reported in Moccia, Widmer \& Cozzolino (2007) using fluorescent dye-labeled primers. Approximately $250 \mathrm{ng}$ of genomic DNA was digested with $E c o$ RI and $M s e I$ restriction endonucleases, and then ligated with the appropriate adaptors. A pre-selective amplification of restriction fragments was conducted using a tem of $1 \mu \mathrm{L}$ of restriction-ligation product and with EcoRIA + MseIA or MseIC as primers. After a preliminary screening for the variability and reproducibility, five selective combinations were chosen for this study: EcoRIA-MseICGG, EcoRIA-MseIACT, EcoRIA-MseICCAA, EcoRIA-MseICGTA, EcoRIA-MseIACTG.

The selective amplifications were conducted with $1 \mu \mathrm{L}$ of a 1:10 dilution of preamplification product.

Separation and detection took place on a 3130 Genetic Analyzer (Applied Biosystems, Foster City, CA, USA). GeneScan-500 LIZ (Applied Biosystems) was used as IS (internal standard). The electrophoregram generated by the sequencer was analysed using the GeneMapper version 3.7 software package (2004; Applied Biosystems). Clear and unambiguous peaks, between 50 and $500 \mathrm{bp}$, were considered as AFLP markers and scored as present or absent in order to generate a binary data matrix. DNA of both allopatric species was amplified and run in duplicate to validate repeatability. The AFLP analysis was performed considering two data sets: the first, contained the Botton plants group + allopatric (plate-Bt), and the second contained the Bois Niau plants group + allopatric (plate-BN). These two data sets were run and scored independently.

We calculated FST values to estimate the population differentiation using the software AFLP-SURV v. 1.0 (Vekemans, 2002). Genetic structure was explored using Principal Coordinates Analysis (PCoA) in GENALEX (Peakall \& Smouse, 2006). We performed a Bayesian clustering analysis that allows to estimate the number of genetic clusters (i.e., populations), allele frequencies within clusters, and the genetic composition of individuals, by assigning the latter to different groups in which deviations from Hardy-Weinberg equilibrium and linkage equilibrium are minimized (Jacquemyn et al., 2012a). Data were analysed in STRUCTURE v. 2.3.1 (Pritchard, Stephens \& Donnelly, 2000; Falush, Stephens $\&$ Pritchard, 2003) assuming an admixture model and correlated allele frequencies with 50,000 burn-in steps and 100,000 MCMC (Markov chain Monte Carlo) steps and $K=1-10$, with ten independent runs per $K$. The goal was to estimate the $K$ value that best fitted to our data. 
The $K$ value was assessed from the likelihood distribution (STRUCTURE output), which is the number of genetic clusters present in the data. $K$ value fitting best with our data was selected using the $\Delta K$ statistic (Evanno, Regnaut \& Goudet, 2005) produced by STRUCTURE HARVESTER (http://taylor0.biology.ucla.edu/struct_harvest/).

Finally, we used DISTRUCT (Rosenberg, 2004) to graphically display the output obtained with STRUCTURE.

NEWHYBRIDS (Anderson, 2008) was also performed to investigate the genetic profiles of the sympatric zone. We implemented a model that assumed two pure parental species and hybrids. This model assigns posterior probabilities for each individual to belong to one of the possibile six genotypic frequency classes: pure parental species, F1, F2, backcross to each parental species. A burn-in of 100,000 steps followed by run lengths of 1,000,000 steps was used (Jacquemyn et al., 2012a).

Moreover, the Hybrid index was estimated based in order to assess genome-wide admixture (Buerkle, 2005). This method calculated hybrid index (HI) based on a maximum likelihood and ranges between zero and one, corresponding to pure individuals of reference and alternative species, respectively. In our analyses, plants with a $\mathrm{HI}$ ranging between 0 and 0.2 were assigned to P. bifolia, whereas individuals with $\mathrm{HI}$ between 0.8 and 1 were assigned to $P$. chlorantha. We used AFLP data obtained from the allopatric P. bifolia and $P$. chlorantha individuals as parental data, while those obtained from the sympatric area were entered as putatively admixed individuals. This analysis was performed following the same parametric procedure proposed by Jacquemyn et al. (2012a). The plot was produced with the mk.image function in INTROGRESS. The hybrid index was estimated to assess genome-wide admixture using the est.h function ((Jacquemyn et al., 2012a) incorporated in the R program INTROGRESS (Gompert \& Buerkle, 2010). Finally, we correlated the molecular hybrid index with morphological index obtained with the discriminant function (described previously) using Spearman's rho method for non-normally distributed data (Jacquemyn et al., 2012a).

\section{Volatile collection and analyses of floral scents}

In the sympatric zone in Botton, we sampled the volatile compounds emitted by flowers (the entire inflorescence) (Table 1). Floral scents emitted by the sympatric Platanthera species and the intermediate morphotypes were sampled for chemical analyses in the same phenological flower state, using a dynamic headspace adsorption technique during peak flowering time (June-July) and between 21:00 and 01:00 h local time, thereby matching the peak feeding times of most nocturnal moths (Nilsson, 1978). The same individuals were used to sample plant material for genetic analyses. The intact inflorescences were carefully enclosed in modified polyacetate bags (Pingvin frying bags, Art.nr 352: Kalle Nalo $\mathrm{GmbH}$, Wiesbaden, Germany). The air, together with volatiles, was drawn through the bag by a battery-operated membrane pump, with a flow of $100 \mathrm{ml} / \mathrm{min}$, into Teflon-PTFE cartridges containing $85 \mathrm{mg}$ of the adsorbent Tenax-GR, mesh 60/80 (Andersson et al., 2002) for $60 \mathrm{~min}$. Trapped scent compounds were eluted with $100 \mu \mathrm{L}$ of cyclohexan and all samples were stored at $-20^{\circ} \mathrm{C}$. Then, extracts were analysed by Gas Chromatography/Mass Spectrometry (GC-MS) on a Finnigan Trace Ultra GC coupled to a Finnigan POLARIS 
Table 2 Floral traits (Mean, with Standard Deviation) for $P$. bifolia, intermediate morphotypes and $P$. chlorantha for allopatric and sympatric populations.

\begin{tabular}{|c|c|c|c|c|c|c|c|c|}
\hline & \multicolumn{3}{|c|}{ Botton } & \multicolumn{3}{|c|}{ Bois Niau } & \multicolumn{2}{|c|}{ Allopatric pop. } \\
\hline \multirow{3}{*}{ Morphology traits } & P. bifolia & Interm. & P. chlor. & P. bifolia & Interm. & P. chlor. & P. bifolia & P. chlor. \\
\hline & Mean & Mean & Mean & Mean & Mean & Mean & Mean & Mean \\
\hline & $\mathrm{SD}$ & $\mathrm{SD}$ & $\mathrm{SD}$ & $\mathrm{SD}$ & $\mathrm{SD}$ & $\mathrm{SD}$ & $\mathrm{SD}$ & $\mathrm{SD}$ \\
\hline \multirow{2}{*}{ Labellum length (mm) } & 11.41 & 12.31 & 13.5 & 13.07 & 13.47 & 14.26 & 9.18 & 13.76 \\
\hline & 1.8 & 1.32 & 1.49 & 1.39 & 1.23 & 0.66 & 2.45 & 0.28 \\
\hline \multirow{2}{*}{ Spur length (mm) } & 31.04 & 29.74 & 27.98 & 30.16 & 30.63 & 27.4 & 20.1 & 25.72 \\
\hline & 3.83 & 3.4 & 2.99 & 2.88 & 2.18 & 0.71 & 2.64 & 0.43 \\
\hline \multirow{2}{*}{ Caudicle length (mm) } & 0.53 & 0.69 & 1.82 & 0.56 & 0.66 & 1.92 & 0.25 & 1.79 \\
\hline & 0.11 & 0.12 & 0.16 & 0.1 & 0.16 & 0.07 & 0.26 & 0.03 \\
\hline \multirow{2}{*}{ Viscidia distance $(\mathrm{mm})$} & 0.96 & 1.48 & 3.61 & 0.64 & 1.39 & 3.91 & 0.3 & 3.9 \\
\hline & 0.21 & 0.45 & 0.52 & 0.25 & 0.35 & 0.16 & 0.61 & 0.07 \\
\hline
\end{tabular}

$\mathrm{Q}$ ion trap mass and equipped with a Restek RXI-5 MS column (30 m length $\times 0.25 \mathrm{~mm}$ diameter $\times 0.25 \mu \mathrm{m}$ film thickness).

Aliquots of $1 \mu \mathrm{L}$ of the extracts were injected in splitless mode first at $35^{\circ} \mathrm{C}(4 \mathrm{~min}$, followed by a programmed increase of oven temperature to $200^{\circ} \mathrm{C}$ at a rate of $5^{\circ} \mathrm{C} / \mathrm{min}^{-1}$ ) then at $200{ }^{\circ} \mathrm{C}$ for $1 \mathrm{~min}$ with an oven temperature to $270{ }^{\circ} \mathrm{C}$ at a rate of $10^{\circ} \mathrm{C} / \mathrm{min}$. Helium was used as carrier. The proportional abundance of floral scent compounds (relative amounts with respect to aggregate peak areas, excluding contaminants) was calculated on the absolute amounts of compounds. Component peaks in the GC-MS chromatograms were quantified by integration of selected ion currents relative to one internal standard (IS) (2-phenylethanol, $\mathrm{C}_{8} \mathrm{H}_{10} \mathrm{O}$ ). The Xcalibur ${ }^{\mathrm{TM}}$ Software was used and $2 \mu \mathrm{L}$ of the internal standard was added for quantification of five samples of each group randomly chosen. Components were identified by their mass spectral patterns and chromatographic retention data (retention time and relative retention time). Furthermore, components were identified by comparing recorded mass spectra with the NIST08 and Wiley275 spectral databases with a probability of match $>90 \%$.

\section{RESULTS}

\section{Morphology and fruit set}

A preliminary MRPP analysis indicated that the floral morphology was significantly different between allopatric and sympatric groups in Botton $\left(A=0.605, \delta_{\text {obs }}=0.025 \delta_{\text {exp }}=\right.$ $0.065 P<0.001)$ and Bois Niau $\left(A=0.626, \delta_{\text {obs }}=0.026 \delta_{\exp }=0.069 P<0.001\right)$. The ANOSIM analysis was in agreement with the results of the MRPP, since it also showed a significant difference between those groups (Botton: $R=0.762, P<0.001$; Bois Niau $R=0.779, P<0.001$ ). The results of the multiple comparisons with the Kruskal-Wallis and the Dunn's test displayed which trait differed between groups (reported as letters in Fig. 2; Table 2).

Intermediate morphotypes in both sites did not show any significant differences compared to sympatric $P$. bifolia, although values of morphological traits were slightly 

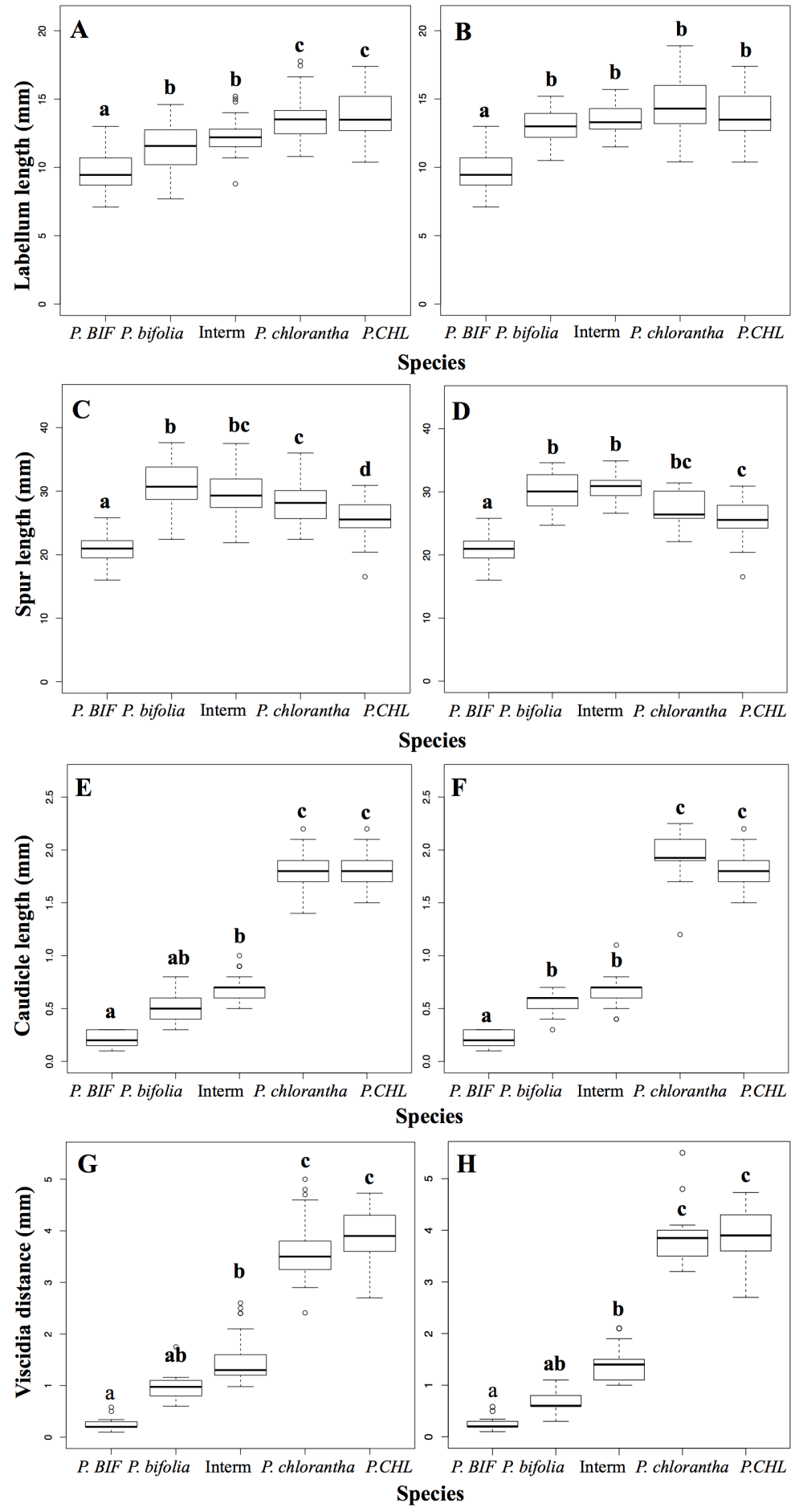

Figure 2 Box plots of floral morphological traits among different taxa and populations. (A, C, E, G): Box plots of allopatric populations and sympatric population of Botton. (B, D, F, H): Box plots of allopatric populations and sympatric population of Bois Niau. Different letters on top of boxplots indicate significant differences. Abbreviations: P. BIF, P. bifolia allopatric; P. CHL, P. chlorantha allopatric. 
higher. Contrarily, comparing to allopatric P. bifolia, intermediate morphotypes showed significant differences for all morphological traits. On the other hand, intermediate morphotypes in Botton displayed significantly smaller values than those of sympatric P. chlorantha, with the exception of spur length; intermediate morphotypes in Bois Niau had significant differences only for viscidia distance and caudicle length.

Nonetheless, comparing intermediate morphotypes of both sites to allopatric P. chlorantha, all traits were significantly different, with the exception of labellum length for Bois Niau plants. Multiple comparisons (Kruskal Wallis and Dunn's test) did not show significant differences between intermediate morphotypes and sympatric P. bifolia for viscidia distance and caudicle length. The differences in these floral traits may be hidden by the extreme morphological values displayed by allopatric populations. We observed that caudicle length and viscidia distance in allopatric $P$. bifolia ranged from 0.1 to 0.3 $\mathrm{mm}$ and 0.1 to $0.58 \mathrm{~mm}$, respectively, whereas the sympatric $P$. bifolia form had caudicle lengths varying between 0.3 and $0.9 \mathrm{~mm}$ and viscidia distances varying between 0.6 and $1.75 \mathrm{~mm}$ (results obtained considered both sites). It thus appears that those morphological characters are significantly different between allopatric and sympatric populations: these correspond to the two ecotypes as mentioned above (introduction).

The discriminant analysis using allopatric populations produced the function $D=0.680$ (caudicle length), +0.689 (viscidia distance), (eigenvalue $=57.119 ; \chi^{2}=150.112$ canonical correlation $=0.991 ; P<0.001)$. Based on these functions, $P$. bifolia individuals received negative scores $(-7.36)$ and $P$. chlorantha positive scores (7.36).

Principal components analysis of flower traits explained $89 \%$ of the variance along its two main axes between allopatric and Botton populations; the first principal component accounted for $63.31 \%$ of the species variation and had high positive loadings with viscidia distance, caudicle length and labellum length. The length of the spur was positively correlated with the second axis and the variation was $26 \%$. The proportion of the explained variance between allopatric and Bois Niau populations was 92\% (Fig. 3) and, the first principal component accounted for $62.97 \%$ of the variation and showed high positive loadings with viscidia distance, caudicle length and labellum length, whereas spur length accounted for $29 \%$ (Fig. 3) on the second axes.

Fruit set differed significantly between sympatric species and intermediate morphotypes in both sites (Botton: $\chi^{2}=12.34 P<0.001$; Bois Niau: $\chi^{2}=9.07 P<0.05$ ). Moreover, we observed a fruit-set advantage of $P$. chlorantha compared to $P$. bifolia in Botton (Dunn's test: $P<0.01$ ) (Fig. 4A) and Bois Niau (Dunn's test: $P<0.05$ ) (Fig. 4B), whereas a significant difference between $P$. bifolia and intermediate morphotypes was observed only in Bois Niau (Dunn's test: $P<0.05)$ (Fig. 4B).

\section{Manual crosses and pre and post-zygotic isolation index}

The proportion of viable seeds obtained from interspecific crosses was not different between $P$. bifolia and $P$. chlorantha and between intraspecific crosses (allopatric populations). The average percentage of viable seeds was: $40 \% \pm 33.8 \%$ SD for P. bifolia and $52.67 \pm$ 37.38\% SD for P. chlorantha. For intraspecific crosses we obtained for P. bifolia a mean of: $41.93 \% \pm 25.68 \% \mathrm{SD}$, and for P. chlorantha: $38.07 \% \pm 30.15 \%$ SD. The proportion 

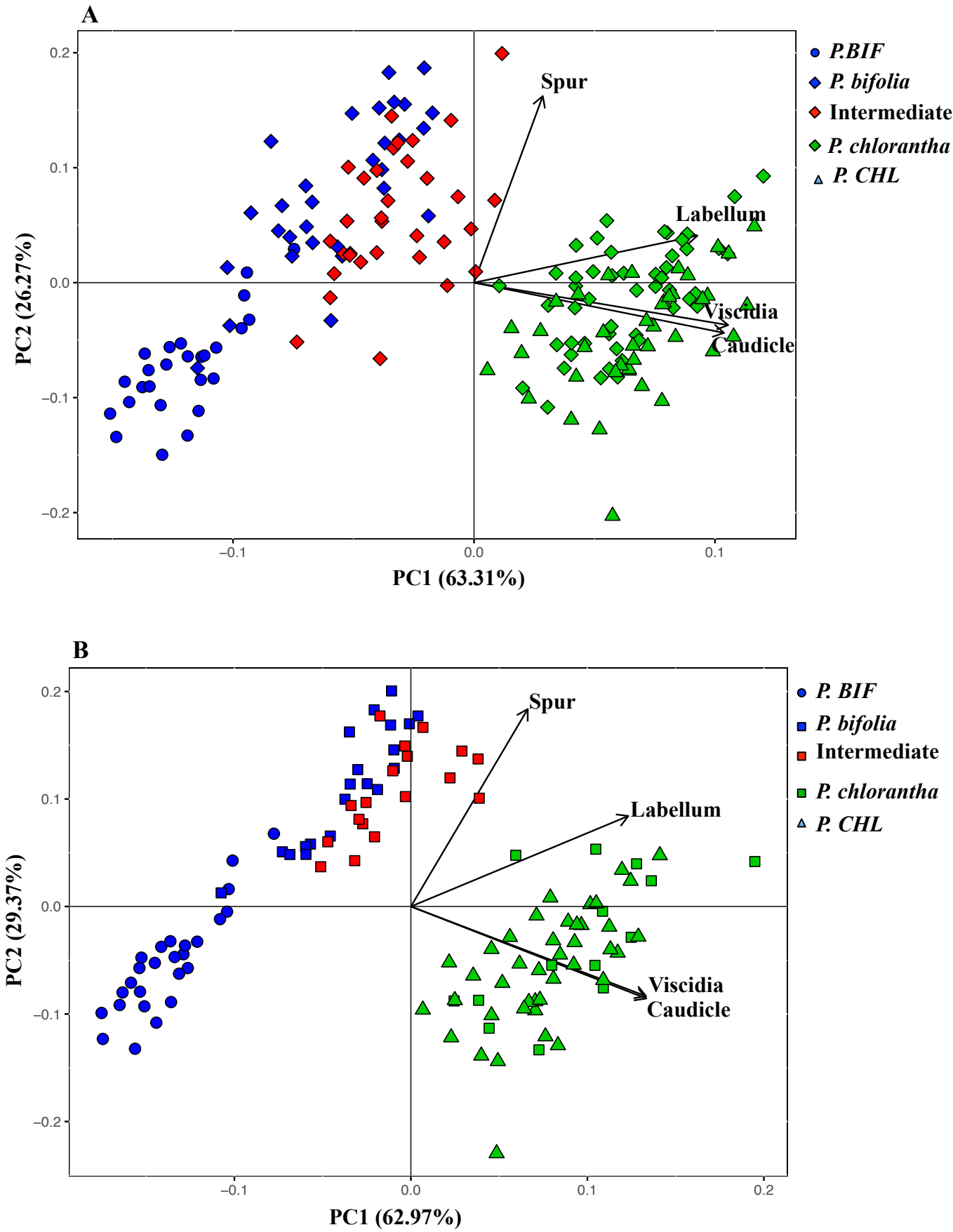

Figure 3 Principal component analysis (PCA) based on morphological flower characteristics of Platanthera allopatric taxa and sympatric population of Botton (A) and Bois Niau (B). Floral characters represented in the PCA are: Spur, length of the spur; Labellum, length of the labellum; Viscidia, distance between the viscidia and Caudicle, length of the caudicle. P. BIF, P. bifolia allopatric; P. CHL, P. chlorantha allopatric. 

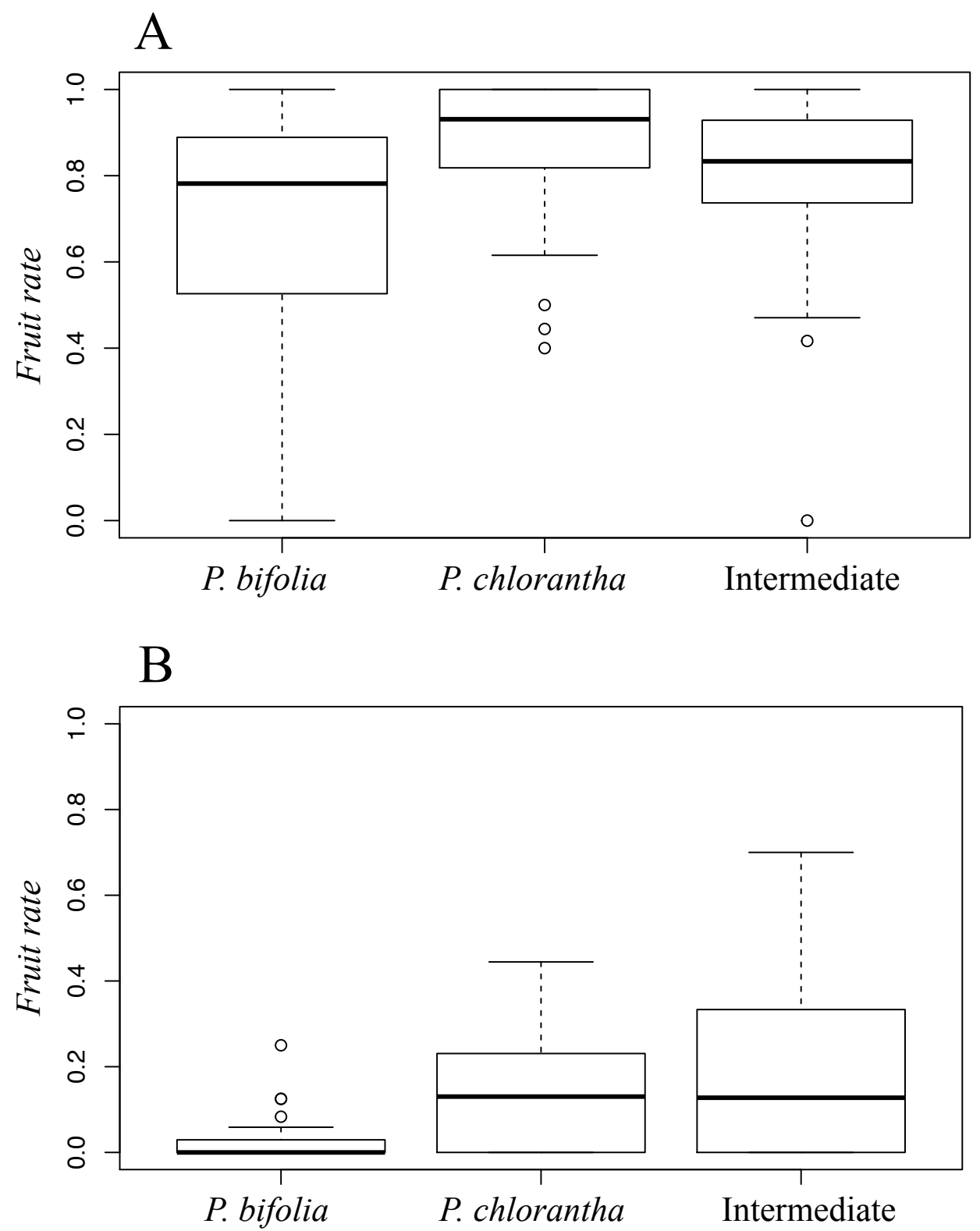

Figure 4 Fruit set in P. bifolia, intermediates and $P$. chlorantha of Botton (A) and Bois (B) Niau sympatric zones. Bars indicate means and standard errors.

of viable seeds was not significantly different between interspecific crosses $(P=0.56)$ and intraspecific crosses $(P=0.32)$. For bi-directional crosses the post-pollination pre-zygotic isolation indices were negative ( $P$. bifolia: $-0.43 ; P$. chlorantha: -0.14$)$, which indicated that interspecies crosses performed better than intraspecies ones. Similarly, the post-pollination post-zygotic isolation indices were also weak, 0.22 for $P$. bifolia/P. chlorantha, and -0.17 for P. chlorantha/P. bifolia. 


\begin{tabular}{|c|c|c|c|c|}
\hline & Locus & P. bifolia & Intermediate & P. chlorantha \\
\hline \multicolumn{5}{|l|}{ Botton } \\
\hline ACGfamCCAA & 61.55 & 0.00 & 0.00 & 1.00 \\
\hline ATAnedCGTA & 65.2 & 0.00 & 0.27 & 1.00 \\
\hline ATAnedCGTA & 81.56 & 0.00 & 0.00 & 1.00 \\
\hline ATAnedCGTA & 105.72 & 1.00 & 0.77 & 0.00 \\
\hline ACGfamCCAA & 117.45 & 1.00 & 0.77 & 0.00 \\
\hline ACGfamCCAA & 316.75 & 0.00 & 0.00 & 1.00 \\
\hline \multicolumn{5}{|l|}{ Bois Niau } \\
\hline ATAnedCGG & 70.85 & 0.00 & 0.00 & 1.00 \\
\hline ATAnedCGG & 72.15 & 1.00 & 1.00 & 0.00 \\
\hline ATAnedCGG & 77.22 & 0.00 & 0.00 & 1.00 \\
\hline ATAnedCGG & 100.96 & 0.00 & 0.17 & 1.00 \\
\hline ATAnedCGG & 106.95 & 1.00 & 0.66 & 0.00 \\
\hline ATAnedCGG & 112.54 & 0.00 & 0.00 & 1.00 \\
\hline AGGfamACT & 64.66 & 0.00 & 0.00 & 1.00 \\
\hline ACGfamCCAA & 61.55 & 0.00 & 0.05 & 1.00 \\
\hline
\end{tabular}

Self-pollination tests revealed a very low level of autonomous self-pollination in allopatric and sympatric populations analysed, since we observed just one flower forming a fruit on a sympatric individual of $P$. bifolia (out of 12 plants), but without viable seeds.

The overall period of flowering between P. bifolia and P. chlorantha largely coincided. For 21 days $P$. bifolia and $P$. chlorantha were flowering at the same time. More precisely, $P$. bifolia flowered from 4 th of June to 29th of June, while the flowering period of $P$. chlorantha lasted from 22th of May to 24th of June. Therefore, P. bifolia flowered for 26 days and 34 for $P$. chlorantha. Therefore, $\mathrm{RI}_{\text {phenology }}=1-(21 / 26)=0.19$ for $P$. bifolia, and $\mathrm{RI}_{\text {phenology }}=1-(21 / 34)=0.38$ for $P$. chlorantha.

\section{Genetic diversity and differentiation}

For the genetic analyses we excluded samples with a high number of missing values. Therefore, these analyses were carried out only on 28 allopatric individuals, 46 sympatric individuals in plate-Bt and 33 allopatric individuals, 43 sympatric individuals in plate- $\mathrm{Bn}$. A total of 87 (plate-Bt) and 100 (plate-BN) polymorphic bands were detected in this study. The mean percentage of polymorphic loci was $79 \%$ for Botton and $76 \%$ for Bois Niau. We identified six and eight species-specific polymorphic bands in plate-Bt and plate-BN respectively; intermediate morphotypes showed the same polymorphism of $P$. bifolia for these species-specific sites (Table 3).

Pairwise $F_{\mathrm{ST}}$ values were high between the intermediate morphotypes and $P$. chlorantha populations $\left(F_{\mathrm{ST}}=0.14\right.$ plate-Bt and $F_{\mathrm{ST}}=0.16$ plate-Bn $)$, but considerably lower between the intermediate population and $P$. bifolia $\left(F_{\mathrm{ST}}=0.01\right.$ plate-Bt and $F_{\mathrm{ST}}=0.02$ plate-Bn).

In the principal coordinates analysis ( $\mathrm{PCoA}$ ) the first two axes explained $54 \%$ of variance for Botton and $57 \%$ of variance for Bois Niau population (Fig. 5). The PCoA 


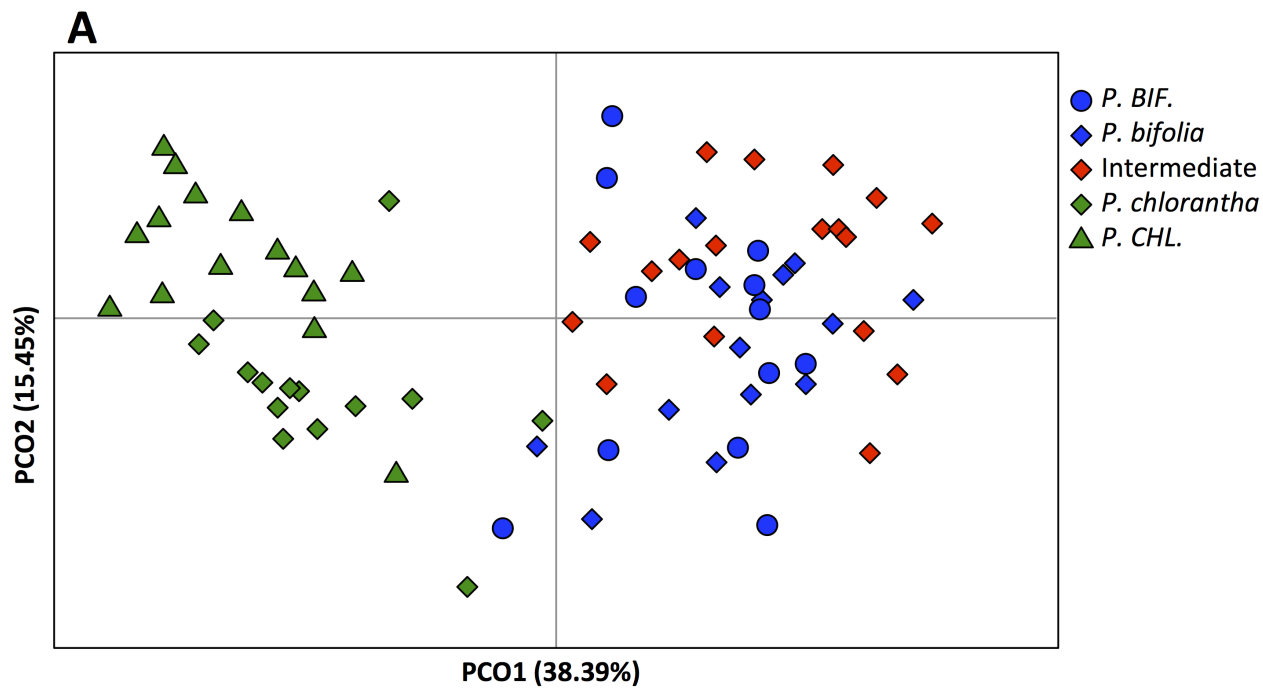

B

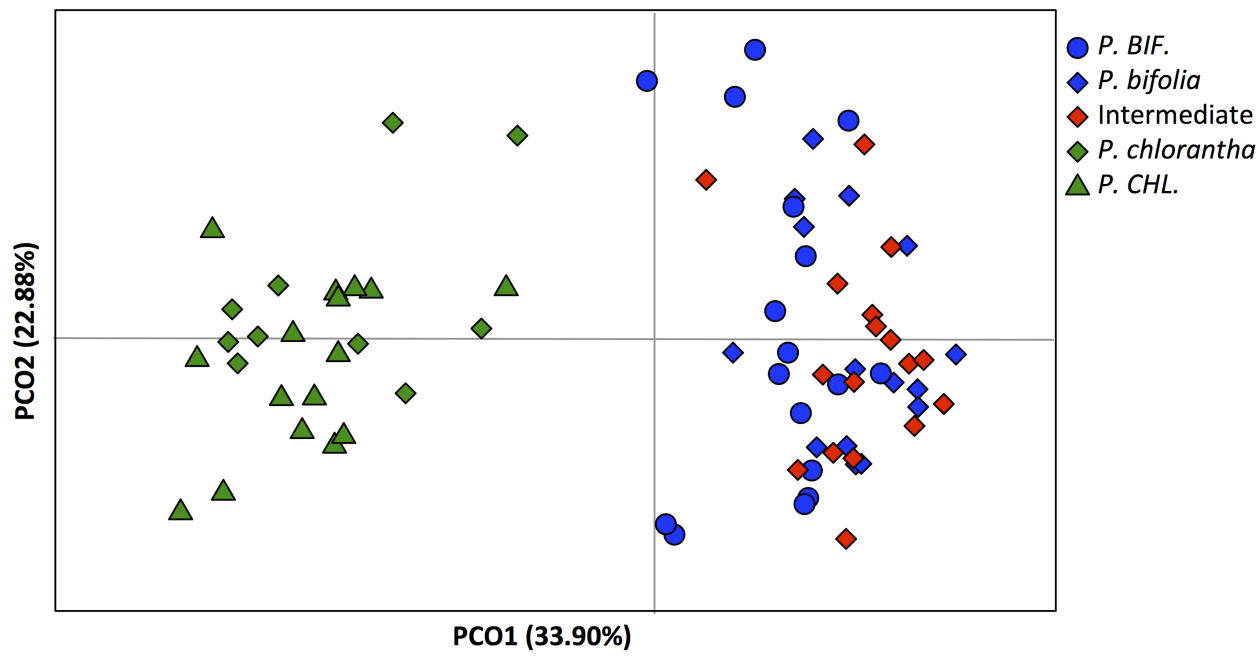

Figure 5 Principal Coordinates Analyses (PCoA) based on AFLP of Platanthera allopatric taxa and sympatric population of Botton (A) and Bois Niau (B). Abbreviations: P. BIF, P. bifolia allopatric and P. CHL, P. chlorantha allopatric.

Full-size DOI: $10.7717 /$ peerj.4256/fig-5

clearly separated $P$. bifolia from $P$. chlorantha along the first axis, although there is a very slight overlap in the case of Botton plants. Moreover, PCoA plots for both plates identified two groups: (1) the intermediate morphotypes with allopatric and sympatric P. bifolia, and (2) the sympatric and allopatric P. chlorantha (Fig. 5).

The results obtained from the Bayesian admixture analyses with STRUCTURE (Fig. 6) showed that the likelihood $(\operatorname{Ln} P(D))$ increased greatly at $K=2$ which, together with the fact that $\Delta K$ reached its maximum at $K=2$, suggests the existence of only two genetic clusters for both plates (Fig. 6). Population clustering showed a consistent pattern indicating two independent genetic clusters: P. bifolia and the intermediate morphotypes formed a single cluster separated from $P$. chlorantha (Fig. 6). 
A

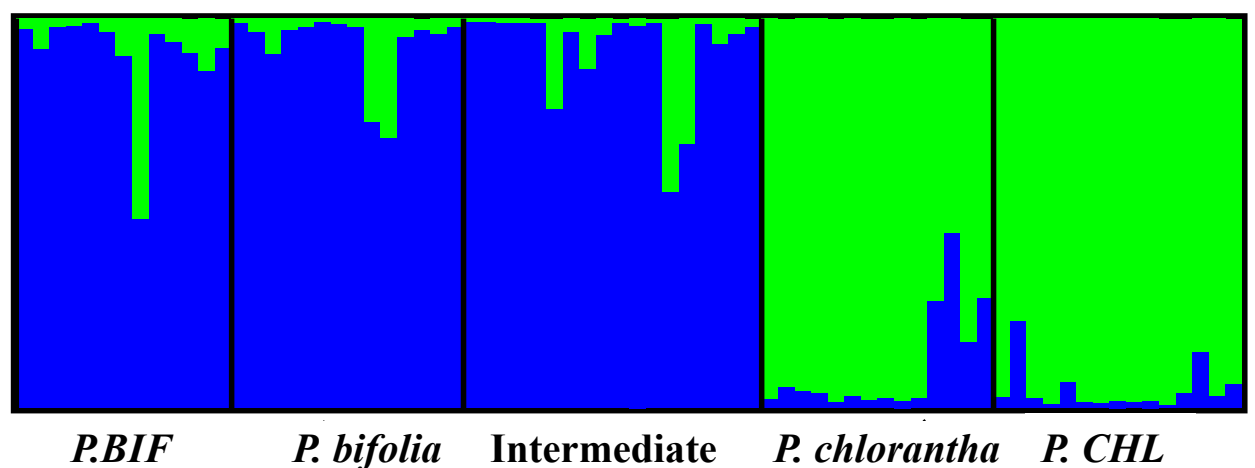

B

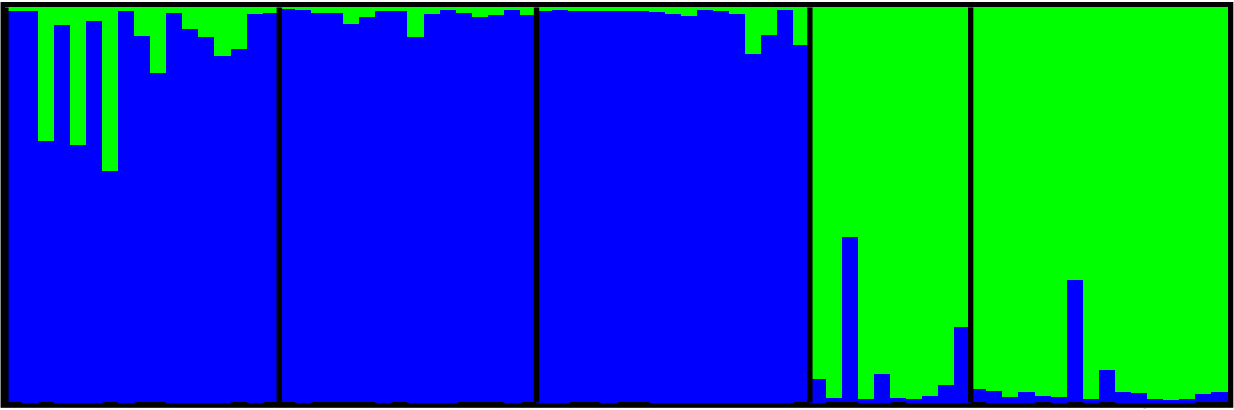

P.BIF P. bifolia Intermediate P. chlorantha P. CHL

Figure 6 The structure of both sympatric populations inferred by Bayesian clustering is showed using STRUCTURE software $(K=2)$ with DESTRUCT output. Columns represent individuals, while colours represent the proportion of their genome assigned to each of the two clusters. (A): Botton population + allopatric taxa, (B): Bois Niau population + allopatric taxa. Abbreviations: P. BIF, P. bifolia allopatric and P. CHL, P. chlorantha allopatric.

Full-size DOI: 10.7717/peerj.4256/fig-6

NEWHYBRIDS yielded similar results by assigning the intermediate morphotypes to the group of $P$. bifolia and revealing a low proportion of admixture genome in sympatric populations. Considering a threshold $q$-value of 0.9 , we observed that $83 \%$ and $93 \%$ of individuals sampled in Botton and Bois Niau respectively were unequivocally assigned to P. bifolia and P. chlorantha and only four plants in Botton and one plants in Bois Niau that were identified as intermediate morphotype, had an admixed gene pool (Fig. 7).

In Bois Niau sympatric population all plants identified morphologically as $P$. bifolia and intermediate morphotypes had an hybrid index ranging between 0 and 0.2 supporting the previous results, whereas in Botton population most of them had an hybrid index ranging between 0 and 0.2 and only four individuals showed an hybrid index ranging between 0.3 and 0.4. Individuals firstly morphologically identified as P. chlorantha showed a hybrid index ranging between 0.4 and 0.7 in both sympatric populations.

Finally, molecular and morphological hybrid indices were significantly $(P<0.001)$ correlated in both sympatric sites (Fig. 8). 

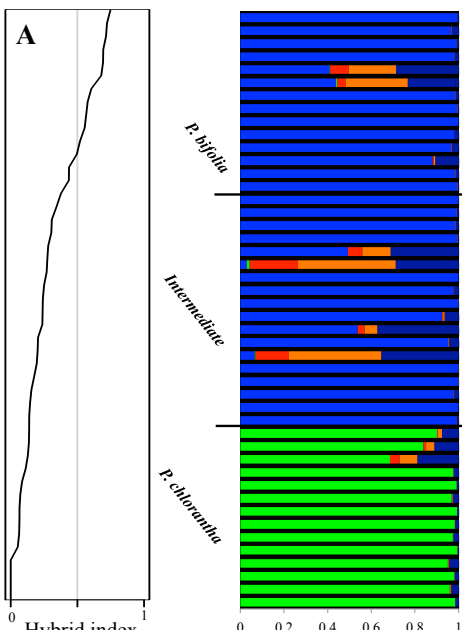

P. bifolia
P. chloranth

$\square$ P. chlo
$\square$ F1
$\square$ F2

Backcross P. bifolia

Backcross P. chlorantha
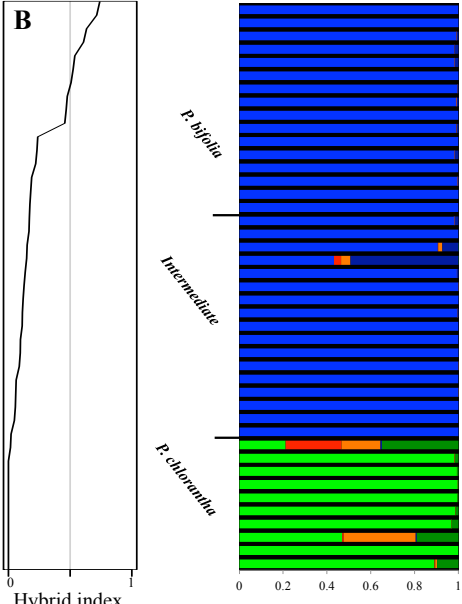

口. Pifolia

$\square$ P. chlorantha

$\square \mathrm{F} 1$

Backcross P. bifolia

Backcross P. bifolia

Figure 7 Hybrid Index of sympatric populations (A: Botton; B: Bois Niau) and Bayesian inference of genotype class estimated with NEWHYBRIDS. Hybrid Index of sympatric populations is showed on the left (A: Botton; B: Bois Niau). On the right, Bayesian inference of genotype class estimated with NEWHYBRIDS. Colors represent the genotype classes and individuals are represented as rows. Within each row the extent of the component colors show the posterior probability of an individual with respect to each genotype class and the a priori group assignment is also displayed.

Full-size DOI: 10.7717/peerj.4256/fig-7
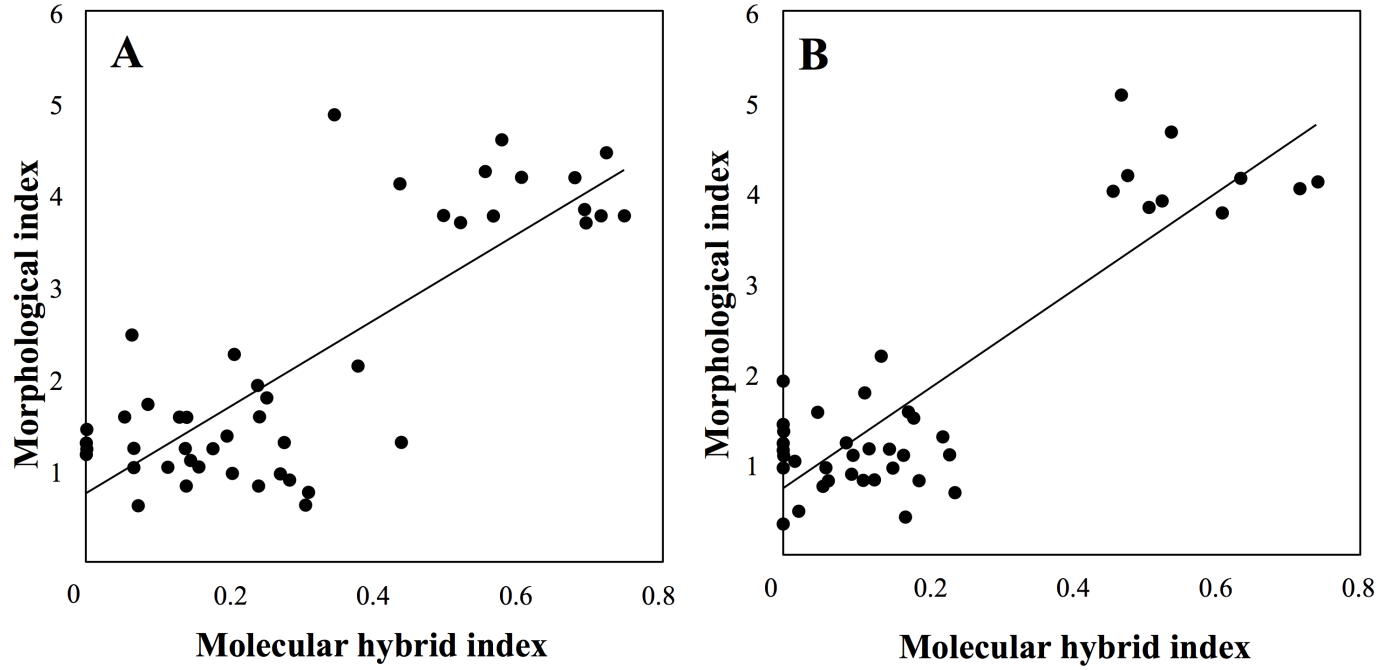

Figure 8 Correlation between molecular and morphological hybrid indices in sympatric sites (A: Botton; B: Bois Niau).

Full-size DOI: 10.7717/peerj.4256/fig-8 
Table 4 Floral scent profile (mean, standard deviation and occurrence) of bouquets emitted by the inflorescences of $\boldsymbol{P}$. bifolia and $\boldsymbol{P}$. chloranth $\boldsymbol{a}$ and the intermediate morphotypes. The table shows the relative amounts (in \%) of odour compounds in headspace fractions of the different taxa.

\begin{tabular}{|c|c|c|c|}
\hline \multirow{4}{*}{ Volatile compounds (\%) } & P. bifolia & Intermediate & P. chlorantha \\
\hline & Mean & Mean & Mean \\
\hline & $\mathrm{SD}$ & $\mathrm{SD}$ & $\mathrm{SD}$ \\
\hline & Occurrence & Occurrence & Occurrence \\
\hline Total number of individuals & 10 & 7 & 10 \\
\hline \multirow{3}{*}{ 3,7-Dimethyl-1,3,6-octatriene } & 30.39 & 13.81 & 11.34 \\
\hline & 8.96 & 18.22 & 20.14 \\
\hline & 10 & 3 & 4 \\
\hline \multirow{3}{*}{ 1,2-Hexanediol-2-benzoate } & 23.5 & 39.92 & 0 \\
\hline & 15.05 & 31.02 & 0 \\
\hline & 10 & 7 & 0 \\
\hline \multirow{3}{*}{ Santolinatriene } & 36.1 & 33.5 & 0.03 \\
\hline & 19.45 & 26.88 & 0.09 \\
\hline & 9 & 5 & 3 \\
\hline \multirow{3}{*}{ 3,7-Dimethyl-2,6-octadien-1-ol } & 9.76 & 12.25 & 0 \\
\hline & 5.66 & 6.15 & 0 \\
\hline & 10 & 7 & 0 \\
\hline \multirow{3}{*}{ 3-Carene } & 0 & 0 & 13.16 \\
\hline & 0 & 0 & 15.61 \\
\hline & 0 & 0 & 9 \\
\hline \multirow{3}{*}{ Benzyl acetate } & 0.17 & 0.26 & 0 \\
\hline & 0.54 & 0.14 & 0.01 \\
\hline & 1 & 6 & 1 \\
\hline \multirow{3}{*}{ 3,7-Dimethyl-2,6-octadien-1-ol acetate } & 0 & 0 & 1.67 \\
\hline & 0.54 & 0.07 & 2.63 \\
\hline & 0 & 0 & 6 \\
\hline \multirow{3}{*}{ Lilac aldehyde } & 0 & 0.13 & 69.91 \\
\hline & 0 & 0.29 & 15.63 \\
\hline & 0 & 2 & 10 \\
\hline \multirow{3}{*}{ Lilac alcohol } & 0.08 & 0.14 & 3.88 \\
\hline & 0.16 & 0.16 & 2.64 \\
\hline & 3 & 4 & 10 \\
\hline
\end{tabular}

\section{Floral scents}

Based on the group of compounds that dominated a scent profile, the bouquets emitted by the inflorescences of $P$. bifolia, $P$. chlorantha and the intermediate morphotypes included a total of ten volatile compounds: two benzenoids and eight monoterpenoids (Table 4).

The following classes could be distinguished: lilac aldehydes, alcohol compounds, geraniolic compounds, and benzenoid compounds. Compared with P. bifolia, the scent patterns within $P$. chlorantha populations were less variable. Nevertheless, individuals of the two species showed a divergent chemical pattern. Specifically, the mean of relative percentage of lilac aldehyde in $P$. chlorantha was higher compared with the sympatric 
P. bifolia (Table 4), in contrast with the results of Tollsten \& Bergström (1993) where $P$. chlorantha contained a higher percentage of lilac aldehyde. Furthermore, among the ten volatile compounds identified, the relative amount of three compounds (ocimene, 1,2-hexanediol-2-benzoate and santolina triene) was emitted in high percentage only by P. bifolia and the intermediate morphotypes compared with the P. chlorantha population. Also other compounds were dominant, such as benzenoids in P. bifolia compared with P. chlorantha (Table 4), which was in accordance with the results of Tollsten \& Bergström (1993). By contrast, the floral compound 3,7-Dimethyl-1,3,6-octatriene is present in a high percentage in P.bifolia compared to the intermediate morphotypes and P. chlorantha species. This compound was observed to be pheromone involved in social regulation in a honeybee colony (Maisonnasse et al., 2010) but not directly involved in attraction of nocturnal moths (http://www.pherobase.com/database/compound/compounds-detailcis-beta-ocimene.php).

MRPP analysis indicates that floral scents were significantly differentiated among groups in floral scent composition $(A=0.551, \delta$ obs $=0.262, \delta \exp =0.583, P<0.001)$. The ANOSIM analysis was in accordance with the result of MRPP analysis, which showed a significant difference between Platanthera groups $(R=0.748, P<0.001)$. Moreover, Tukey's Honest Significant Differences and post-hoc test revealed that there was a significant difference in the variance dispersion of floral scents between $P$. bifolia and $P$. chlorantha $(P=0.002)$ and between $P$. chlorantha and intermediate morphotypes $(P=0.011)$.

The analysis of overall floral odour similarity with HCAST produced a dendrogram which shows that investigated sympatric populations are resolved into two clusters that were supported statistically (AU values $>80 \%$ ) (Fig. 9). The first cluster contained the sympatric $P$. chlorantha and the second two subclusters contained intermediate and P. bifolia individuals sympatric with them. The results of this analysis show a significant similarity of chemical patterns in floral scent composition with $P$. bifolia of all intermediate morphotypes sampled (Fig. 9).

\section{DISCUSSION}

Platanthera individuals with intermediate shape column (gynostemium width/length) have been observed and described in several geographical areas (in Sweden, Nilsson, 1983; Nilsson, 1985; Plepys, Ibarra \& Lofstedt, 2002b; Maad \& Nilsson, 2004; in Netherlands, Claessens \& Kleynen, 2006; Durka et al., 2017; in Austria, Perko, 1997; Künkele \& Baumann, 1998; in Germany and Belgium, Durka et al., 2017). Exceptional situations with putative isolated hybrids or with a limited numbers of parental species have also been observed (Perko, 1997; Perko, 2004; Claessens \& Kleynen, 2006; Durka et al., 2017).

Our morphological analyses confirmed the expectations with intermediate morphotypes diplaying significant differences in column morphology between both Platanthera species. We also observed that the allopatric population of P. bifolia exhibited more extremes values of floral column compared to the sympatric one. The multivariate analysis (PCA) showed that the analysed floral characters were exhaustively discriminant between the two Platanthera species, which were represented in two separate clusters, where intermediate morphotypes were closer to P. bifolia group (Fig. 3). 


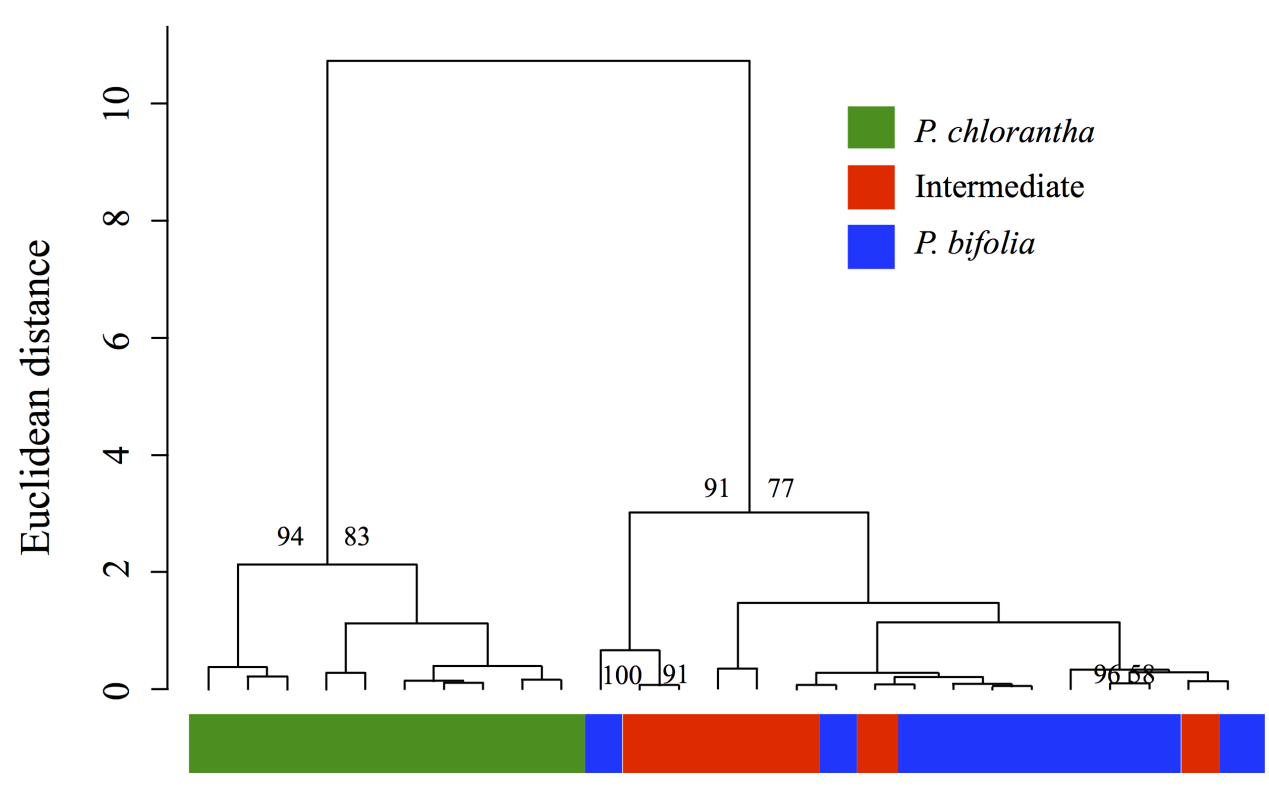

Figure 9 Cluster dendrogram produced by hierarchical cluster analysis. Cluster dendrogram produced by hierarchical cluster analysis with Ward's method using Euclidean distances among floral scent samples (relative proportions in \% of the total blend) of the Platanthera sympatric groups investigated. Approximately Unbiased (AU) Ps $>80 \%$ are indicated above the branches of the dendrogram.

Full-size DOI: 10.7717/peerj.4256/fig-9

Our molecular investigations (AFLP) also revealed a good separation between the two Platanthera species (PCoA), but in this case, plants with intermediate floral morphological traits, could not be genetically separated from P. bifolia (full overlap of AFLP's profiles) (Fig. 5). Similarly, the analyses with STRUCTURE and NEWHYBRIDS revealed two distinct clusters, one containing $P$. bifolia and intermediate morphotypes and the other containing P. chlorantha species (Fig. 6).

Accordingly, the Hybrid Index analysis confirmed that intemediate morphotypes belong to P. bifolia group, showing an average value of hybrid index of 0.1 considering both sympatric sites. On the other hand, individuals firstly morphologically identified as $P$. chlorantha showed a hybrid index ranging between 0.4 and 0.7 . This unexpected result could be probably due to the high genetic differentiation between allopatric $P$. chlorantha that we considered as reference species in INTROGRESS and the two sympatric populations as confirmed from the Fst values (Botton: 0.12; Bois Niau: 0.14). Another hypothesis has been proposed basing on the assumption of Bateman, James \& Rudall (2012), who explored both nuclear and plastid genomes in P. bifolia and P. chlorantha, by identifing only one variable site in the ITS region (not species-specific) that distinguished the two species. The evidence for $P$. chlorantha being derived relative to $P$. bifolia comes from phylogenetic comparison with other closely related species of Platanthera, i.e., those included in the ITS tree of Bateman et al. (2009). Accordingly to this statement, the maximum 0.7 value of $P$. chlorantha obtained in INTROGRESS could reveal that most of $P$. bifolia genome is contained in $P$. chlorantha and the exclusive loci, since they are shared between the two species, would be few. 
Moreover, molecular analyses also revealed that about $17 \%$ and $7 \%$ of all sampled individuals displayed an admixed gene pool, indicating that hybridization and introgression between the two taxa had occurred in both sympatric sites.

The few intermediate genotypes observed in the studied sympatric populations may be the result of an ancestral polymorphism that persists in the sister species (incomplete lineage sorting) or the result of an asymmetric gene flow, which may depend on the relative sizes of the two sympatric populations and of the various species of pollinating moths. It is already known that evolution may occur at the level of loci (Wu, 2001; Nosil \& Schluter, 2011) and hybrid forms often represent a transitional phase in a much larger dynamic exchange of genetic material between parental lines, via backcrossing and introgression (Gompert \& Buerkle, 2010; McIntosh et al., 2014). We can also hypothesize that hybridization between these two studied species is restricted to certain stochastic events.

Nevertheless, since most of these intermediate morphotypes unequivocally belonged to $P$. bifolia gene pool, the most likely scenario that could explain this situation might be that, within the genetic background of $P$. bifolia, recent selection acting on a genetic polymorphism would lead to a modification of the morphology of floral column. Thus, we supported the hypothesis of Bateman, James \& Rudall (2012) according to which a gymnostemium widening could reflect a mutation of a very limited number of genes that are involved in the phenotypic shift from $P$. bifolia to $P$. chlorantha. We also suspected that this limited number of genes might be also responsible for the variation in gynostemium width in intermediate P. bifolia individuals. However, several examples of morphological versus molecular divergence have also been recorded in other European orchid clades (Bateman et al., 2003; Pellegrino et al., 2005; Bateman et al., 2011). One example could be represented by Dactylorhiza incarnata aggregate, which was rich in phenotypic diversity (Bateman \& Denholm, 1983) but shows little or no variation in allozymes, ITS sequences, plastid haplotypes or even AFLPs (Hedrén, Fay \& Chase, 2001), even though more recent studies by Hedrén (2009) have revealed greater, and more structured, molecular differences among ecotypes of D. incarnata.

Additionally, genetic compatibility between P. bifolia and P. chlorantha was found through manual interspecific crosses experiments, where the proportion of viable seeds was not different between the two species and not significantly higher compared to intraspecific crosses. The estimation of post-pollination pre and post-zygotic indices indicated that interspecific crosses performed better than intraspecific ones, suggesting that species were not completely isolated.

Furthermore, since the association with mycorrhizal fungi may contribute to maintaining a post-zygotic isolation barrier between the orchid species (Jacquemyn et al., 2010; Jacquemyn et al., 2012b; Reinhart, Wilson \& Rinella, 2012; Bateman et al., 2014), in a previous study (Esposito et al., 2016), we showed that in our studied sympatric populations, mycorrhizal fungi were most likely not directly involved in maintaining species boundaries.

Overall, besides the substantial area of sympatry and the evident reproductive compatibility, we also observed that flowering phenology did not largely differ between the two species. The overlap in flowering phenology is high (RI close to zero), and it is unlikely to contribute to reproductive isolation between the two species. Moreover, the 
flowering time of intermediate morphotypes preceded the one of the sympatric P. bifolia, (even if this difference was rather small) and follows the sympatric P. chlorantha. Despite the apparent lack of strong post-pollination barriers, remarkably similar distributions and a considerable overlap in ecological preferences, Bateman, James \& Rudall (2012) considered surprising the fact that both Platanthera species did not co-occur more often as well as the significant paucity of confident records of hybrids between the two species.

Given all these considerations, we may speculate that the low rate of introgressed genotypes found in sympatry could be due to a combination of several pre-pollination isolation barriers, and their potentially complex interactions. In Orchidaceae, prepollination mechanisms seem generally to be particularly good at achieving isolation in sympatry despite often sharing pollinators (Dressler, 1968; Cozzolino et al., 2005; Cozzolino $\&$ Scopece, 2008), and these barriers have been often described, on average, to be twice as strong as post-pollination ones, by contributing more to total isolation (Martin \& Willis, 2007; Rieseberg \& Willis, 2007; Lowry et al., 2008; Widmer, Lexer \& Cozzolino, 2009; Baack et al., 2015). For example, floral odour may represent a mechanism preventing that both species interbreed randomly, and as a pre-pollination barrier, may play a crucial role in upholding species isolation in sympatry (Grant, 1949; Grant, 1994).

Our chemical investigation of floral scent profiles in sympatry corroborated the genetic results on the belonging of those morphological intermediate individuals to $P$. bifolia. More precisely, it revealed that $P$. chlorantha group differed considerably in floral compounds from $P$. bifolia, whereas the intermediate morphotypes presented a similar chemical profile to P. bifolia (Table 4-except for 3,7-dimethyl-1, 3,6-octatriene which is in common with P. chlorantha). These findings of were broadly in agreement with previous studies on floral scent composition of Platanthera (Nilsson, 1983; Nilsson, 1985). Monoterpenes were, indeed, the most abundant compounds in the floral bouquets of all studied populations for $P$. chlorantha individuals; the floral scent was essentially composed of lilac aldehydes and alcohols. In contrast, a mixture of monoterpenes and aromatic esters was observed in P. bifolia. Nilsson (1983) suggested that the presence of lilac compounds in P. chlorantha could be an adaptation to noctuid moths, and aromatic esters in P. bifolia to sphingid moth pollination.

Also Tollsten \& Bergström (1993) observed the divergence in floral scent composition between Platanthera species, by hypothesizing that floral scent might reflect variations in the local pollinator fauna (noctuid, geometrid, as well as sphingid moths), which may lead to an "ethological isolation". However, Tollsten \& Bergström (1993) also pointed out that different populations of $P$. bifolia with contrasting pollinator spectra, actually possessed indistinguishable scent cocktails. Such an observation, of course, does not favour the idea that divergence of $P$. chlorantha with respect to P. bifolia would be driven by (subtle) divergence in scent blends.

Furthermore, the evolution of pre-pollination incompatibility among plants species (and populations) is thought to be associated with the specialized relationships with pollinators (Stebbins, 1970), and the divergence in column's morphology in Platanthera species may represent a significant mechanical barrier (Nilsson, 1983). Specializations to various methods of pollination by the same type of pollinator was already known in this 
genus (Efimov, 2011). In Platanthera species, the morphological divergence, in particular the distance between the viscidia, determine the attachement of the pollinia on different parts of the pollinator's head (eyes or proboscis). The pre-pollination barrier due to pollinators may not be as hermetic as usually thought. Indeed, a noctuid species, namely Cucullia umbratica, was observed as a pollinator of intermediate individuals (Claessens, Gravendeel \& Kleynen, 2008). The same species was also observed by us, visiting and pollinating intermediate as well as P. bifolia and P. chlorantha individuals, in the same populations as studied in this article (Esposito, Merckx \& Tyteca, 2017).

However, some speculations have been made in order to explain the presence and the persistence of intermediate morphotypes in sympatry which displayed a morphologically hybrid's resemblance of column morphology and a genetical patterns shared with P. bifolia group. We may hypothesize, for instance, a system where the phenotype of a group remains unchanged, while selection seems to act only on the phenotype of the second group and bringing about a resemblance to the first group, by describing a typical scenario of advergent evolution (Johnson, Alexandersson \& Linder, 2003). This system could be estabilished in our study population, through which $P$. bifolia individuals tend to acquire $P$. chlorantha-like floral characteristics in sympatry. In plants, advergent evolution is primarily influenced by pollinators, which select flowers on the basis of their conditioned preferences (Chittka \& Thompson, 2001).

Moreover, we may also speculate that among P. bifolia plants, the individuals tending towards $P$. chlorantha' s phenotype may be positively selected in order to attract and exploit the pollinators of this species. The analysis of female success, indeed, showed a significantly higher fruit set in P. chlorantha compared to P. bifolia in both sympatric sites (Fig. 4).

These results may also suggest a slightly higher fruit set of intermediate forms compared to P. bifolia group (Fig. 4B). Indeed, since reproductive success depends on the interaction between pollinators and column length, a better fit between them, may influence fruit rate through better pollinaria removal and deposition, and can shape the evolution of interspecific floral variation. Particularly, considering that pollinators penetrate the spur via its entrance, the distance separating the viscidia will be a crucial trait that dictate which potential pollinator will be the most efficient in transferring pollen among flowers, by influencing strongly the reproductive success. Moreover, in a previous study conducted by Hapeman \& Inoue (1997), the column morphology of Platanthera is considered evolutionary labile and easily shifted when subjected to pollinator-mediated selection.

Interestingly, the results of a study recently published by Durka et al. (2017), who investigated the morphological and genetic variation between both Platanthera species and morphologically intermediate individuals (found isolated from parental species) in Germany, the Netherlands and Belgium, revealed the presence of three independent gene pools represented by $P$. chlorantha, $P$. bifolia and plants referred to as non-hybrid intermediates, which although phenotypically intermediate, were not of hybrid origin. Nevertheless, the existence of these intermediate plants as pure and autonomous populations genetically distinct could be explained by a genetic drift. By contrast, our observed populations of intermediate plants in Belgium are still mixed with P. bifolia, thus the reasons of their presence and persistence still remain an open question. 
Thus, to provide better knowledge whether these sympatric Platanthera species just respond plastically to environmental conditions or are in a process of early speciation and specialization to local pollinators, further studies that will consider the evolutionary drivers of reproductive isolation and genomic basis of adaptive traits in natural populations, need also to be conducted.

\section{CONCLUSIONS}

We may confirm that analyses based exclusively on morphological data are likely to fail to recognize hybrids accurately (Rieseberg \& Ellstrand, 1993). The availability and the increasing ease of development of molecular markers have facilitated studies of potential cases of hybridization and introgression (Rieseberg \& Ellstrand, 1993; Martinsen et al., 2001). A number of studies conducted on orchid species using molecular markers have confirmed the great utility of the latter (Moccia, Widmer \& Cozzolino, 2007; Pinheiro et al., 2010; Pinheiro et al., 2015; Pavarese et al., 2011).

In this study, we investigated two sympatric contact zones between two closely related Platanthera species and we observed that individuals with intermediate morphology were genetically belonging to $P$. bifolia group. However, the assignment of these individuals as $P$. bifolia species has been more reliable only by providing a much more detailed picture of the genetic structure of a sympatric zone through the use of genome wide analysis.

Overall, we found a low rate of hybridization/introgression, together with an apparent lack of strong post-pollination isolation mechanisms, which allow us to speculate that it could be due to a combination of pre-pollination isolation barriers. Thus, it would be interesting to explore if variation in gynostemium morphology among species is the simple result of plasticity or may reflect adaptive evolution in response to pollinator-mediated selection.

This may be possible by conducting a selection study in sympatry in order to evaluate the presence of phenotypic selection acting on floral characters related to both sex functions in the context of different kinds of local pollinator's composition. These kinds of studies might provide a better framework for understanding patterns of pollinator-mediated selection or hypothetical advergent evolution in Platanthera sympatric species.

\section{ACKNOWLEDGEMENTS}

We thank Thomas Merckx, Thomas Henneresse and Guy Deflandre for field assistance, Laurent Grumiau for lab assistance (chemical analysis) and Manon Martin for statistical support. We greatly appreciate the critical and constructive comments from Renate Wesselingh and Salvatore Cozzolino on earlier versions of the manuscript, as well as Richard Bateman, Barbara Gravendeel and anonymous reviewers for later versions. This is paper BRC 382 from the Biodiversity Research Centre of UCL. 


\section{APPENDIX}

Photographies deposited in the Herbarium of the Belgian National Botanic Garden, Meise (BR). In the author's number, "DT", Daniel Tyteca; "FE”, Fabiana Esposito.

\begin{tabular}{|c|c|c|c|c|c|}
\hline Taxon & Locality & Collection date & $\begin{array}{l}\text { Author's } \\
\text { number }\end{array}$ & BR reference & $\begin{array}{l}\text { Correspondence } \\
\text { in article }\end{array}$ \\
\hline \multirow[t]{5}{*}{ P. bifolia } & Navaugle & 1st July, 2012 & DT_0404 & BR0000025789065V & \\
\hline & Navaugle & 1st July, 2012 & DT_0440 & BR0000025789072V & \\
\hline & Navaugle & 8 July, 2013 & DT_0701 & BR0000025789089V & Fig. 1A \\
\hline & Navaugle & 8 July, 2013 & DT_0703 & BR0000025789096V & \\
\hline & Bois Niau & 3 June, 2011 & DT_0980 & BR0000025789003V & Fig. 1B \\
\hline \multirow[t]{6}{*}{ Intermediate } & Bois Niau & 3 June, 2011 & DT_0974 & BR0000025788990V & \\
\hline & Bois Niau & 21 June, 2010 & DT_0836 & BR0000025789010V & \\
\hline & Bois Niau & 21 June, 2010 & DT_0840 & BR0000025789027V & \\
\hline & Botton & 25 May, 2011 & DT_0947 & BR0000025789034V & Fig. 1C \\
\hline & Botton & 25 May, 2011 & DT_0953 & BR0000025789041V & \\
\hline & Botton & 25 May, 2011 & DT_0958 & BR0000025789058V & Fig. 1D \\
\hline \multirow[t]{4}{*}{ P. chlorantha } & Bois Niau & 21 June, 2010 & DT_0850 & BR0000025789102V & Fig. 1E \\
\hline & Botton & 18 May, 2007 & DT_0035 & BR0000025789119V & \\
\hline & Transinne & 4 July, 2013 & FE_4196 & BR0000025789126V & Fig. 1F \\
\hline & Transinne & 4 July, 2013 & FE_4222 & BR0000025789133V & \\
\hline
\end{tabular}

\section{ADDITIONAL INFORMATION AND DECLARATIONS}

\section{Funding}

This study was supported by grants-in-aid from the Fonds Scientifique de Recherche of the Université catholique de Louvain for two years between 2013 and 2015. The funders had no role in study design, data collection and analysis, decision to publish, or preparation of the manuscript.

\section{Grant Disclosures}

The following grant information was disclosed by the authors:

Fonds Scientifique de Recherche of the Université catholique de Louvain.

\section{Competing Interests}

The authors declare there are no competing interests.

\section{Author Contributions}

- Fabiana Esposito conceived and designed the experiments, performed the experiments, analyzed the data, wrote the paper, prepared figures and/or tables, reviewed drafts of the paper.

- Nicolas J. Vereecken conceived and designed the experiments, performed the experiments, analyzed the data, contributed reagents/materials/analysis tools, wrote the paper, prepared figures and/or tables, reviewed drafts of the paper. 
- Maddalena Gammella analyzed the data, wrote the paper, reviewed drafts of the paper.

- Rosita Rinaldi and Pascal Laurent performed the experiments, analyzed the data, contributed reagents/materials/analysis tools.

- Daniel Tyteca conceived and designed the experiments, performed the experiments, wrote the paper, prepared figures and/or tables, reviewed drafts of the paper.

\section{Field Study Permissions}

The following information was supplied relating to field study approvals (i.e., approving body and any reference numbers):

Field experiments were approved by the Département de la Nature et des Forêts of the Walloon Region of Belgium.

\section{Data Availability}

The following information was supplied regarding data availability:

The raw data is included in the Supplemental Files and in Tables 1-4 in the manuscript.

\section{Supplemental Information}

Supplemental information for this article can be found online at http://dx.doi.org/10.7717/ peerj.4256\#supplemental-information.

\section{REFERENCES}

Abbott R, Albach D, Ansell S, Arntzen JW, Baird SJE, Bierne N, Boughman J, Brelsford A, Buerkle CA, Buggs R, Butlin RK, Dieckmann U, Eroukhmanoff F, Grill A, Cahan SH, Hermansen JS, Hewitt G, Hudson AG, Jiggins C, Jones J, Keller B, Marczewski T, Mallet J, Martinez-Rodriguez P, Most M, Mullen S, Nichols R, Nolte AW, Parisod C, Pfennig K, Rice AM, Ritchie MG, Seifert B, Smadja CM, Stelkens R, Szymura JM, Vainola R, Wolf JBW, Zinner D. 2013. Hybridization and speciation. Journal of Evolutionary Biology 26:229-246 DOI 10.1111/j.1420-9101.2012.02599.x.

Anderson EC. 2008. Bayesian inference of species hybrids using multilocus dominant genetic markers. Philosophical Transactions of the Royal Society of London B: Biological Sciences 363:2841-2850 DOI 10.1098/rstb.2008.0043.

Andersson S, Nilsson LA, Groth I, Bergström G. 2002. Floral scents in butterflypollinated plants: possible convergence in chemical composition. Botanical Journal of the Linnean Society 140:129-153 DOI 10.1046/j.1095-8339.2002.00068.x.

Arnold ML. 1992. Hybridization as an evolutionary process. Annual Review of Ecology and Systematics 23:237-261 DOI 10.1146/annurev.es.23.110192.001321.

Baack E, Melo MC, Rieseberg LH, Ortiz-Barrientos D. 2015. The origins of reproductive isolation in plants. New Phytologist 207:968-984 DOI 10.1111/nph.13424.

Bateman RM. 2005. Circumscribing and interpreting closely related orchid species: Platanthera dactylorhiza and the crucial role of mutation. Journal of the Hardy Orchid Society 2:104-111.

Bateman RM, Bradshaw E, Devey DS, Glover BJ, Malmgren S, Sramko G, Thomas MM, RudalL PJ. 2011. Species arguments: clarifying concepts of species delimitation in 
the pseudo-copulatory orchid genus Ophrys. Botanical Journal of the Linnean Society 165:336-347 DOI 10.1111/j.1095-8339.2011.01121.x.

Bateman RM, Denholm I. 1983. A reappraisal of the British and Irish dactylorchids, 1. The tetraploid marsh-orchids. Watsonia 14:347-376.

Bateman RM, Hollingsworth PM, Preston J, Luo YB, Pridgeon AM, Chase MW. 2003. Molecular phylogenetics and evolution of Orchidinae and selected Habenariinae (Orchidaceae). Botanical Journal of Linnean Society 142:1-40 DOI 10.1046/j.1095-8339.2003.00157.x.

Bateman RM, James KE, Luo YB, Lauri RK, Fulcher T, Cribb PJ, Chase MW. 2009. Molecular phylogenetics and morphological reappraisal of the Platanthera clade (Orchidaceae: Orchidinae) prompts expansion of the generic limits of Galearis and Platanthera. Annals of Botany 104:431-445 DOI 10.1093/aob/mcp089.

Bateman RM, James KE, Rudall PJ. 2012. Contrast in levels of morphological versus molecular divergence between closely related Eurasian species of Platanthera (Orchidaceae) suggests recent evolution with a strong allometric component. New Journal of Botany 2:110-148 DOI 10.1179/2042349712Y.0000000013.

Bateman RM, Rudall PJ, Bidartondo MI, Cozzolino S, Tranchida-Lombardo V, Carine MA, Moura M. 2014. Speciation via floral heterochrony and presumed mycorrhizal host switching of endemic butterfly orchids on the Azorean archipelago. American Journal of Botany 101:979-1001 DOI 10.3732/ajb.1300430.

Bateman RM, Sexton R. 2008. Is spur length of Platanthera species in the British Isles adaptively optimized or an evolutionary red herring? Watsonia 27:1-21.

Baum A, Baum H. 2017. Platanthera muelleri-eine dritte Art in der Platanthera bifolia/chlorantha Gruppe in Mitteleuropa. Journal EuropäIscher Orchideen 49:133-152.

Boberg E, Ågren J. 2009. Despite their apparent integration, spur length but not perianth size affects reproductive success in the moth-pollinated orchid Platanthera bifolia. Functional Ecology 23:1022-1028 DOI 10.1111/j.1365-2435.2009.01595.x.

Boberg E, Alexandersson R, Jonsson M, Maad J, Ågren J, Nilsson LA. 2014. Pollinator shifts and the evolution of spur length in the moth-pollinated orchid Platanthera bifolia. Annals of Botany 113:267-275 DOI 10.1093/aob/mct217.

Brzosko E. 2003. The dynamics of island populations of Platanthera bifolia in the Biebrza National Park (NE Poland). Annales Botanici Fennici 40:243-253.

Buerkle CA. 2005. Maximum-likelihood estimation of a hybrid index based on molecular markers. Molecular Ecology Notes 5:684-687 DOI 10.1111/j.1471-8286.2005.01011.x.

Chittka L, Thompson JD. 2001. Cognitive ecology of pollination. Cambridge: Cambridge University Press.

Claessens J, Gravendeel B, Kleynen J. 2008. Cucullia umbratica L. als Bestaüber von Platanthera $\mathrm{x}$ hybrida Bruegg. in Süd-Limburg (Niederlande). Journal Europäischer Orchideen 40:73-84.

Claessens J, Kleynen J. 2006. Anmerkungen zur Hybridbildung bei Platanthera bifolia und P. chlorantha. Journal Europäischer Orchideen 938:3-28. 
Cortis P, Vereecken NJ, Schiestl FP, Lumaga MRB, Scrugli A, Cozzolino S. 2009. Pollinator convergence and the nature of species' boundaries in sympatric Sardinian Ophrys (Orchidaceae). Annals of Botany 104:497-506 DOI 10.1093/aob/mcn219.

Coyne JA, Orr HA. 2004. Speciation. Sunderland: Sinauer Associates.

Cozzolino S, D'Emerico S, Widmer A. 2004. Evidence for reproductive isolate selection in Mediterranean orchids: karyotype differences compensate for the lack of pollinator specificity. Proceedings of the Royal Society B: Biological Sciences 271:259-262 DOI 10.1098/rspb.2003.2600.

Cozzolino S, Nardella AM, Impagliazzo S, Widmer A, Lexer C. 2006. Hybridization and conservation of Mediterranean orchids: should we protect the orchid hybrids or the orchid hybrid zones? Biological Conservation 129:14-23 DOI 10.1016/j.biocon.2005.09.043.

Cozzolino S, Schiestl FP, Müller A, De Castro O, Nardella AM, Widmer A. 2005. Evidence for pollinator sharing in Mediterranean nectar-mimic orchids: absence of premating barriers? Proceedings of the Royal Society of London B: Biological Sciences 272:1271-1278 DOI 10.1098/rspb.2005.3069.

Cozzolino S, Scopece G. 2008. Specificity in pollination and consequences for postmating reproductive isolation in deceptive Mediterranean orchids. Philosophical Transactions of the Royal Society of London B: Biological Sciences 363:3037-3046 DOI 10.1098/rstb.2008.0079.

Cozzolino S, Widmer A. 2005. Orchid diversity: an evolutionary consequence of deception? Trends in Ecology and Evolution 20:487-494 DOI 10.1016/j.tree.2005.06.004.

Dafni A, Ivri Y. 1979. Pollination ecology of, and hybridization between, Orchis coriophora L. and O. collina Sol. ex Russ. (Orchidaceae) in Israel. New Phytologist 83:181-187 DOI 10.1111/j.1469-8137.1979.tb00740.x.

Darwin C. 1862. On the various contrivances by which British and foreign orchids are fertilised by insects. London: John Murray.

Delforge P. 2006. Orchids of Europe, North Africa and the Middle East. London: A and C Black.

Doyle JJ, Doyle JL. 1987. A rapid DNA isolation procedure for small quantities of fresh leaf tissue. Phytochemical Bulletin 19:11-15.

Dressler RL. 1968. Observations on orchids and euglossine bees in Panamá and Costa Rica. Revista de Biologia Tropical 13:143-183.

Durka W, Baum A, Michalski SG, Baum H. 2017. Darwin's legacy in Platanthera: are there more than two species in the Platanthera bifolia/chlorantha group? Plant Systematics and Evolution 303:419-431.

Edens-Meier R, Bernhardt P. 2014. Darwin's orchids: then and now. Chicago: University of Chicago Press.

Efimov PG. 2011. An intriguing morphological variability of Platanthera s.l. European Journal of Environmental Sciences 1:125-136 DOI 10.14712/23361964.2015.55.

Esposito F, Jacquemyn H, Waud M, Tyteca D. 2016. Mycorrhizal fungal diversity and community composition in two closely related Platanthera (Orchidaceae) Species. PLOS ONE 11(10):e0164108 DOI 10.1371/journal.pone.0164108. 
Esposito F, Merckx T, Tyteca D. 2017. Noctuid moths as potential hybridization agents for Platanthera orchids. Lankesteriana 17:383-393 DOI 10.15517/lank.v17i3.31576.

Evanno G, Regnaut S, Goudet J. 2005. Detecting the number of clusters of individuals using the software STRUCTURE: a simulation study. Molecular Ecology 14:2611-2620 DOI 10.1111/j.1365-294X.2005.02553.x.

Falush D, Stephens M, Pritchard JK. 2003. Inference of population structure using multilocus genotype data: linked loci and correlated allele frequencies. Genetics 164:1567-1587.

Gompert Z, Buerkle CA. 2010. INTROGRESS: a software package for mapping components of isolation in hybrids. Molecular Ecology Resources 10:378-384 DOI 10.1111/j.1755-0998.2009.02733.x.

Grant V. 1949. Pollination systems as isolating mechanisms in angiosperms. Evolution 3:82-97 DOI 10.1111/j.1558-5646.1949.tb00007.x.

Grant V. 1994. Modes and origins of mechanical and ethological isolation in angiosperms. Proceedings of the National Academy of Sciences of the United States of America 91:3-10 DOI 10.1073/pnas.91.1.3.

Hapeman JR, Inoue K. 1997. Plant pollinator interactions and floral radiation in Platanthera (Orchidaceae). In: Givnish TJ, Sytsma KJ, eds. Molecular evolution and adaptive radiation. Cambridge: Cambridge University Press, 433-454.

Hedrén M. 2009. Plastid DNA haplotype variation in Dactylorhiza incarnata (Orchidaceae): evidence for multiple independent colonization events into Scandinavia. Nordic Journal of Botany 27:69-80 DOI 10.1111/j.1756-1051.2009.00274.x.

Hedrén M, Fay MF, Chase MW. 2001. Amplified fragment length polymorphisms (AFLP) reveal details of polyploid evolution in Dactylorhiza (Orchidceae). American Journal of Botany 88:1868-1880 DOI 10.2307/3558363.

Hultén E, Fries M. 1986. Atlas of North European vascular plants (North of the Tropic of Cancer). Vol. I-III. Königstein, Germany: Koeltz Scientific Books.

Ishizaki S, Abe T, Ohara M. 2013. Mechanisms of reproductive isolation of interspecific hybridization between Trillium camschatcense and T. tschonoskii (Melanthiaceae). Plant Species Biology 28:204-214 DOI 10.1111/j.1442-1984.2012.00378.x.

Jacquemyn H, Brys R, Cammue BPA, Honnay O, Lievens B. 2010. Mycorrhizal associations and reproductive isolation in three closely related Orchis species. Annals of Botany 107:347-356 DOI 10.1093/aob/mcq248.

Jacquemyn H, Brys R, Honnay O, Roldán-Ruiz I. 2012a. Asymmetric gene introgression in two closely related Orchis species: evidence from morphometric and genetic analyses. BMC Evolutionary Biology 12:178 DOI 10.1186/1471-2148-12-178.

Jacquemyn H, Brys R, Lievens B, Wiegand T. 2012b. Spatial variation in belowground seed germination and divergent mycorrhizal associations correlate with spatial segregation of three co-occurring orchid species. Journal of Ecology 100:1328-1337 DOI 10.1111/j.1365-2745.2012.01998.x.

Jersáková J, Johnson SD, Kindlmann P. 2006. Mechanisms and evolution of deceptive pollination in orchids. Biological Reviews of the Cambridge Philosophical Society 81:219-235 DOI 10.1017/S1464793105006986. 
Johnson SD, Alexandersson R, Linder HP. 2003. Phylogenetic and experimental evidence for floral mimicry in a guild of fly-pollinated plants. Biological Journal of the Linnean Society 80:289-304 DOI 10.1046/j.1095-8312.2003.00236.x.

Johnson SD, Linder HP, Steiner KE. 1998. Phylogeny and radiation of pollination systems in Disa (Orchidaceae). American Journal of Botany 85:402-411 DOI 10.2307/2446333.

Kay KM. 2006. Reproductive isolation between two closely related hummingbirdpollinated neotropical gingers. Evolution 60:538-552.

Künkele S, Baumann H. 1998. Platanthera bifolia (L.) Rich. X P. chlorantha (Custer) Rchb. = Platanthera X hybrida Brügger 1882. In: Sebald O, Seybold S, Philippi G, Wörz A, eds. Die Farn- und Blütenpflanzen Baden-Württembergs. Vol. 8. Stuttgart: Ulmer Verlag, 456-458.

Lexer C, Fay MF, Joseph JA, Nica MS, Heinze B. 2005. Barrier to gene flow between two ecologically divergent Populus species, P. alba (white poplar) and P. tremula (European aspen): the role of ecology and life history in gene introgression. Molecular Ecology 14:1045-1057 DOI 10.1111/j.1365-294X.2005.02469.x.

Lowry DB, Modliszewski JL, Wright KM, Wu CA, Willis JH. 2008. The strength and genetic basis of reproductive isolating barriers in flowering plants. Philosophical Transactions of the Royal Society B-Biological Sciences 363:3009-3021 DOI 10.1098/rstb.2008.0064.

Ma YP, Xie WJ, Sun WB, Marczewski T. 2016. Strong reproductive isolation despite occasional hybridization between a widely distributed and a narrow endemic Rhododendron species. Scientific Report 6:19146 DOI 10.1038/srep19146.

Maad J. 2002. Selection and floral evolution in Platanthera bifolia and P. chlorantha (Orchidaceae). In: Acta Univ. Ups. comprehensive summaries of uppsala dissertations from the faculty of science and technology. 685. Uppsala: Acta Universitatis Uppsaliensis, 26 pp.

Maad J, Nilsson LA. 2004. On the mechanism of floral shifts in speciation: gained pollination efficiency from tongue- to eye-attachment of pollinia in Platanthera (Orchidaceae). Biological Journal of the Linnean Society 83:481-495 DOI 10.1111/j.1095-8312.2004.00406.x.

Maad J, Reinhammar LG. 2004. Incidence of geitonogamy differs between two populations in the hawkmoth-pollinated Platanthera bifolia (Orchidaceae). Canadian Journal of Botany 82:1586-1593 DOI 10.1139/b04-124.

Maisonnasse A, Lenoir JC, Beslay D, Crauser D, Le Conte Y. 2010. E- $\beta$-ocimene, a volatile brood pheromone involved in social regulation in the honey bee colony (Apis mellifera). PLOS ONE 5(10):e13531 DOI 10.1371/journal.pone.0013531.

Marques I, Draper D, Riofrío L, Naranjo C. 2014. Multiple hybridization events, polyploidy and low postmating isolation entangle the evolution of neotropical species of Epidendrum (Orchidaceae). BMC Evolutionary Biology 14:20 DOI 10.1186/1471-2148-14-20. 
Martin NH, Willis JH. 2007. Ecological divergence associated with mating system causes nearly complete reproductive isolation between sympatric Mimulus species. Evolution 61:68-82 DOI 10.1111/j.1558-5646.2007.00006.x.

Martinsen GD, Whitam TG, Turek RJ, Kaim P. 2001. Hybrid populations selectively filter gene introgression between species. Evolution 55:1325-1335 DOI 10.1111/j.0014-3820.2001.tb00655.x.

McCune B, Grace JB. 2002. Analysis of ecological communities. Oregon: MjM Software Design, Gleneden Beach.

McIntosh EJ, Rossetto M, Weston PH, Wardle GM. 2014. Maintenance of strong morphological differentiation despite ongoing natural hybridization between sympatric species of Lomatia (Proteaceae). Annals of Botany 113:861-872 DOI 10.1093/aob/mct314.

Mielke PW, Berry KJ. 2001. Permutation methods: a distance function approach. Berlin: Springer.

Moccia MD, Widmer A, Cozzolino S. 2007. The strength of reproductive isolation in two hybridizing food-deceptive orchid species. Molecular Ecology 16:2855-2866 DOI 10.1111/j.1365-294X.2007.03240.x.

Nilsson LA. 1978. Pollination ecology and adaptation in Platanthera chlorantha (Orchidaceae). Botaniska Notiser 131:35-51.

Nilsson LA. 1983. Processes of isolation and introgressive interplay between Platanthera bifolia (L.) Rich and P. chlorantha (Custer) Reichb. (Orchidaceae). Botanical Journal of the Linnean Society 87:325-350 DOI 10.1111/j.1095-8339.1983.tb00997.x.

Nilsson LA. 1985. Characteristics and distribution of intermediates between Platanthera bifolia and P. chlorantha (Orchidaceae) in the Nordic countries. Nordic Journal of Botany 5:407-419.

Nosil P, Schluter D. 2011. The genes underlying the process of speciation. Trends in Ecology \& Evolution 26:160-167 DOI 10.1016/j.tree.2011.01.001.

Oksanen J, Blanchet FG, Kindt R, Legendre P, Minchin PR, O'Hara RB, Simpson GL, Solymos P, Henry M, Stevens H, Wagner H. 2012. Vegan: Community Ecology Package. R package version 2.0-5.

Pavarese G, Tranchida-Lombardo V, Cogoni A, Cristaudo A, Cozzolino S. 2011. Where do Sardinian orchids come from: a putative African origin for the insular population of Platanthera bifolia var. Kuenkelei? Botanical Journal of the Linnean Society 167:466-475 DOI 10.1111/j.1095-8339.2011.01190.x.

Peakall R, Smouse PE. 2006. GENALEX 6: genetic analysis in Excel. Population genetic research for teaching and research. Molecular Ecology Notes 6:288-295 DOI 10.1111/j.1471-8286.2005.01155.x.

Pellegrino G, D'Emerico S, Musacchio A, Scrugli A, Cozzolino S. 2005. Confirmation of hybridization among sympatric insular populations of Orchis mascula and O. provincialis. Plant Systematics and Evolution 251:131-142 DOI 10.1007/s00606-004-0235-y.

Perko M. 1997. Beobachtungen zu einigen Hybriden aus der Familie der Orchideen (Orchidaceae) in Kärnten 352 / Österreich, inkl. Dactylorhiza x juennensis M. Perko, nothosp. nat. nov. Carinthia II 187/107:89-101. 
Perko M. 2004. Die orchideen Kärntens. Klagenfurt: Arge Naturschutz.

Pinheiro F, Barros F, Palma-Silva C, Meyer D, Fay MF, Suzuki RM, Lexer C, Cozzolino S. 2010. Hybridization and introgression across different ploidy levels in the Neotropical orchids Epidendrum fulgens and E. puniceoluteum (Orchidaceae). Molecular Ecology 19:3981-3994 DOI 10.1111/j.1365-294X.2010.04780.x.

Pinheiro F, Cardoso-Gustavson P, Suzuki RM, Abrão MCR, Guimarães LRS, Draper D, Moraes AP. 2015. Strong postzygotic isolation prevents introgression between two hybridizing Neotropical orchids Epidendrum denticulatum and E. fulgens. Evolutionary Ecology 29:229-248 DOI 10.1007/s10682-015-9753-z.

Plepys D, Ibarra F, Francke W, Lofstedt C. 2002a. Odour-mediated nectar foraging in the silver Y moth, Autographa gamma (Lepidoptera: Noctuidae): behavioural and electrophysiological responses to floral volatiles. Oikos 99:75-82 DOI 10.1034/j.1600-0706.2002.990108.x.

Plepys D, Ibarra F, Lofstedt C. 2002b. Volatiles from flowers of Platanthera bifolia (Orchidaceae) attractive to the silver Y moth, Autographa gamma (Lepidoptera: Noctuidae). Oikos 99:69-74 DOI 10.1034/j.1600-0706.2002.990107.x.

Pritchard JK, Stephens M, Donnelly P. 2000. Inference of population structure using multilocus genotype data. Genetics 155(2):945-959.

R Core Team. 2015. R: a language and environment for statistical computing. Vienna: R foundation for statistical computing. Available at http://www.R-project.org.

Reinhart KO, Wilson GWT, Rinella MJ. 2012. Predicting plant responses to mycorrhizae: integrating evolutionary history and plant traits. Ecology Letters 15:689-695 DOI 10.1111/j.1461-0248.2012.01786.x.

Rieseberg LH. 1995. The role of hybridization in evolution: old wine in new skins. American Journal of Botany 82:944-953 DOI 10.2307/2445981.

Rieseberg LH, Ellstrand NC. 1993. What can molecular and morphological markers tell us about plant hybridization? Critical Reviews in Plant Sciences 12:213-241 DOI 10.1080/07352689309701902.

Rieseberg LH, Willis JH. 2007. Plant Speciation. Science 317:910-914 DOI 10.1126/science.1137729.

Rosenberg NA. 2004. DISTRUCT: a program for the graphical display of population structure. Molecular Ecology Notes 4:137-138.

Royston JP. 1982. An Extension of Shapiro and Wilk's $W$ test for normality to large samples. Applied Statististics 31:115-124 DOI 10.2307/2347973.

Schatz B, Geoffroy A, Dainat B, Bessière JM, Buatois B, Hossaert-McKey M, Selosse MA. 2010. A case of study of modified interactions with symbionts in a hybrid mediterranean orchid. American Journal of Botany 97:1278-1288 DOI 10.3732/ajb.0900303.

Schlüter PM, Schiestl FP. 2008. Molecular mechanisms of floral mimicry in orchids. Trends in Plant Science 13:228-235 DOI 10.1016/j.tplants.2008.02.008.

Scopece G, Musacchio A, Widmer A, Cozzolino S. 2007. Patterns of reproductive isolation in Mediterranean deceptive orchids. International Journal of Organisms and Evolution 61:2623-2624. 
Soltis PS, Soltis DE. 2009. The role of hybridization in plant speciation. Annual Review of Plant Biology 60:561-588 DOI 10.1146/annurev.arplant.043008.092039.

Stebbins GL. 1959. The role of hybridisation in evolution. Proceedings of the American Philosophical Society 103:231-251.

Stebbins GL. 1970. Adaptive radiation of reproductive characteristics in angiosperms, I: pollination mechanisms. Annual Review of Ecology, Evolution, and Systematics 1:307-326 DOI 10.1146/annurev.es.01.110170.001515.

Stökl J, Schlüter PM, Stuessy TF, Paulus HF, Assum G, Ayasse M. 2008. Scent variation and hybridization cause the displacement of a sexually deceptive orchid species. American Journal of Botany 95:472-481 DOI 10.3732/ajb.95.4.472.

Tollsten L, Bergström LJ. 1993. Fragrance chemotypes of Platanthera (Orchidaceae)the result of adaptation to pollinating moths? Nordic Journal of Botany 13:607-613 DOI 10.1111/j.1756-1051.1993.tb00105.x.

Tremblay R. 1992. Trends in pollination biology of the Orchidaceae: evolution and systematics. Canadian Journal of Botany 70:642-650 DOI 10.1139/b92-083.

Van der Cingel NA. 1995. An atlas of orchid pollination-European orchids. Rotterdam: Balkema.

Vekemans X. 2002. AFLP-SURV version 1.0. Distributed by the author. Laboratoire de Génétique et ecologie végétale. Belgium: Université Libre de Bruxelles.

Vos P, Hogers R, Bleeker M, Reijans M, Van de Lee T, Hornes M, Frijters A, Pot J, Peleman J, Kuiper M, Zabeau M. 1995. AFLP: a new technique for DNA fingerprinting. Nucleic Acids Research 23:4407-4414 DOI 10.1093/nar/23.21.4407.

Waser NM. 2001. Pollinator behaviour and plant speciation: looking beyond the “ethological isolation” paradigm. In: Chittka L, Thomson JD, eds. Cognitive ecology of pollination. Cambridge: Cambridge University Press, 318-335.

Whitney KD, Ahern JR, Campbell LG, Albert LP, King MS. 2010. Patterns of hybridization in plants. Perspectives in Plant Ecology, Evolution and Systematics 12:175-182 DOI 10.1016/j.ppees.2010.02.002.

Widmer A, Lexer C, Cozzolino S. 2009. Evolution of reproductive isolation in plants. Heredity 102:31-38 DOI 10.1038/hdy.2008.69.

Wissemann V. 2007. Plant evolution by means of hybridization. Systematics and Biodiversity 5:242-253 DOI 10.1017/S1477200007002381.

Wu CI. 2001. The genic view of the process of speciation. Journal of Evolutionary Biology 14:851-865 DOI 10.1046/j.1420-9101.2001.00335.x.

Xu S, Schlüter PM, Scopece G, Breitkopf H, Gross K, Cozzolino S, Schiestl FP. 2011. Floral isolation is the main reproductive barrier among closely related sexually deceptive orchids. Evolution 65:2606-2620 DOI 10.1111/j.1558-5646.2011.01323.x. 